IZA DP No. 4290

Inequality and Specialization: The Growth of

Low-Skill Service Jobs in the United States

David H. Autor

David Dorn

July 2009 


\title{
Inequality and Specialization: The Growth of Low-Skill Service Jobs in the United States
}

\author{
David H. Autor \\ $M I T, N B E R$ and IZA
}

David Dorn

CEMFI and IZA

Discussion Paper No. 4290

July 2009

IZA

P.O. Box 7240

53072 Bonn

Germany

Phone: +49-228-3894-0

Fax: +49-228-3894-180

E-mail: iza@iza.org

\begin{abstract}
Any opinions expressed here are those of the author(s) and not those of IZA. Research published in this series may include views on policy, but the institute itself takes no institutional policy positions.

The Institute for the Study of Labor (IZA) in Bonn is a local and virtual international research center and a place of communication between science, politics and business. IZA is an independent nonprofit organization supported by Deutsche Post Foundation. The center is associated with the University of Bonn and offers a stimulating research environment through its international network, workshops and conferences, data service, project support, research visits and doctoral program. IZA engages in (i) original and internationally competitive research in all fields of labor economics, (ii) development of policy concepts, and (iii) dissemination of research results and concepts to the interested public.
\end{abstract}

IZA Discussion Papers often represent preliminary work and are circulated to encourage discussion. Citation of such a paper should account for its provisional character. A revised version may be available directly from the author. 


\title{
ABSTRACT \\ Inequality and Specialization: The Growth of Low-Skill Service Jobs in the United States ${ }^{*}$
}

\begin{abstract}
After a decade in which wages and employment fell precipitously in low-skill occupations and expanded in high-skill occupations, the shape of U.S. earnings and job growth sharply polarized in the 1990s. Employment shares and relative earnings rose in both low and highskill jobs, leading to a distinct U-shaped relationship between skill levels and employment and wage growth. This paper analyzes the sources of the changing shape of the lower-tail of the U.S. wage and employment distributions. A first contribution is to document a hitherto unknown fact: the twisting of the lower tail is substantially accounted for by a single proximate cause - rising employment and wages in low-education, in-person service occupations. We study the determinants of this rise at the level of local labor markets over the period of 1950 through 2005. Our approach is rooted in a model of changing task specialization in which "routine" clerical and production tasks are displaced by automation. We find that in labor markets that were initially specialized in routine-intensive occupations, employment and wages polarized after 1980, with growing employment and earnings in both high-skill occupations and low-skill service jobs.
\end{abstract}

JEL Classification: E24, J24, J31, J62, O33

Keywords: skill demand, job tasks, inequality, polarization, technological change, occupational choice

Corresponding author:

David Dorn

CEMFI

Casado de Alisal 5

28014 Madrid

Spain

E-mail: dorn@cemfi.es

\footnotetext{
"We thank Daron Acemoglu, Joshua Angrist, Kerwin Charles, Luis Garicano, Maarten Goos, Caroline Hoxby, Lawrence Katz, Alan Manning, and numerous seminar participants for excellent suggestions. We thank Amanda Pallais and Jessica Pan for superb research assistance, and Mark Doms and Ethan Lewis for generous assistance with data. We are deeply indebted to Alp Simsek for invaluable assistance with the theoretical model. Autor acknowledges support from the National Science Foundation (CAREER award SES-0239538). Dorn acknowledges funding from the Swiss National Science Foundation.
} 


\section{INTRODUCTION}

A vast body of research documents a steep rise in wage inequality in the United States starting in the 1980s. This spreading of the wage distribution is evident in the upper panel of Figure 1, which plots changes in real hourly wages by percentiles of the hours-weighted earnings distribution using data from the Census Integrated Public Use Microsamples for 1980, 1990 and 2000 (Ruggles et al. 2004). During the 1980s, wage growth was strongly monotone in wage percentiles, with either zero or negative growth in the bottom quartile of the distribution, modest wage growth in the second and third quartiles, and relatively sizable wage growth in the top quartile. This monotone pattern continued in part into the decade of the 1990s, but only in the upper half of the distribution. Wage growth below the median, by contrast, reversed course: wage gains were smallest at the median and monotonically increasing at lower percentiles, giving rise to a U-shaped pattern of wage growth that has been termed 'polarization.'

These diverging patterns of wage growth in the 1980s and 1990s have clear counterparts in contemporaneous changes in the structure of skilled and unskilled employment. The lower panel of Figure 1 plots changes in the share of U.S. employment by occupational skill level, where the skill level of an occupation is proxied by the mean log wages of its workers in $1980 .{ }^{1}$ Akin to the pattern for wages, employment growth in the 1980s was strongly monotone in occupational skill levels: occupations with the lowest skill levels lost employment shares, those in the middle held constant or grew, and occupations in the top quintile expanded substantially. This monotone relationship gave way to 'polarized' employment growth during the 1990s, with occupations in both the bottom and top quintiles of the skill distribution gaining strongly in employment shares at the expense of the middle. ${ }^{2}$

A comparison of changes in wages and changes in employment over these two decades warrants two inferences. First, the clear correspondence between price and quantity movements -i.e., changes in wages and employment by percentile - in both the 1980s and 1990s suggests that demand shifts must play a key role in any economic explanation of the changing structure of wages and employment in both decades. Second, while a rich literature surveyed by Katz and Autor (1999) studies the monotone-inskill rise of U.S. wage and employment inequality during the 1980s, the causal hypotheses explored by that literature neither predict nor explain the twisting of the lower-tail of the wage and employment

\footnotetext{
${ }^{1}$ We use a consistent occupational ranking based on 1980 mean wages to fix a baseline occupational skill level.

${ }^{2}$ Papers by Juhn (1994 and 1999) are the first studies that we are aware of that report evidence of declining demand for 'middle-skill' occupations. Goos and Manning coin the term 'polarization' in a 2003 working paper (Goos and Manning, 2003 and 2007), referring to the polarization of employment in the U.K. Autor Katz, and Kearney (2006, 2008) and Lemieux (2008), find polarization of both employment and, notably, wage growth in the U.S. commencing in the late 1980s. Acemoglu (1999), Spitz-Oener (2006), Dustmann, Ludsteck and Schönberg (2007), and Smith (2008) present further evidence of employment polarization in the UK, West Germany and US, and Goos, Manning and Salomons (2009) find employment polarization in 14 of 16 European OECD countries during using data from 1996 to 2007.
} 
distribution in the subsequent two decades. ${ }^{3}$ Analyzing the proximate and underlying causes of this phenomenon is, we believe, central to understanding the evolving structure of employment and wages in the U.S. and other industrialized economies. ${ }^{4}$

This paper studies both theoretically and empirically the forces behind the changing shape of low-wage and low-skill employment in the U.S. labor market. A first contribution of the paper is to document a hitherto unknown fact: the twisting of the lower tail is substantially accounted for by a single, proximate cause, which is rising employment and wages in a category of work that the Census Bureau classifies as service occupations. Service occupations are jobs that involve assisting or caring for others, including: food service workers; security guards; janitors and gardeners, cleaners; home health aides; child care workers; hairdressers and beauticians, and recreation occupations. ${ }^{5}$ Though among the least educated and lowest paid categories of employment, the share of U.S. labor hours in service occupations grew by 35 percent between 1980 and 2005, after having been flat or declining in the three prior decades (Table 1). ${ }^{6}$ This growth of service occupations stands in striking contrast to declining employment in all similarly low-educated occupation groups (production, craft and repair occupations, operative, fabricator and laborer occupations, and agriculture, forestry and fishing occupations) and instead parallels the growth rate of managerial and professional specialty occupations, the most highly educated occupation group. The rise in service employment was even steeper for non-college workers - those with no more than a high school education. The share of service occupation employment among non-college workers rose by 50 percent between 1980 and 2005, from 13.8 to 20.7 percent, while declining in all other major occupational categories. Simultaneously, real wage growth in service occupations averaged seven percent per decade between 1980 and 2005, substantially exceeding wage growth in other blue collar occupations. ${ }^{7}$

To benchmark the magnitude of the contribution that growth in service occupations makes to employment and wage polarization, we consider a simple counterfactual case where employment and relative wage levels in service occupations are held at their 1980 levels. This counterfactual, shown in

\footnotetext{
${ }^{3}$ Card and DiNardo (2002) and Lemieux (2006) offer critiques of this literature.

${ }^{4}$ Another key difference between the two periods is that the entire locus of wage growth is shifted upward in the 1990s. This movement corresponds to the rapid productivity increases commencing in the mid 1990s (Oliner and Sichel, 2000).

${ }^{5}$ It is critical to distinguish service occupations, a group of low-education occupations providing personal services and comprising 14.3 percent of labor input in 2005 (Table 1), from the service sector, a broad category of industries ranging from health care to communications to real estate and comprising 81 percent of non-farm employment in 2000 (source: www.bls.gov).

${ }^{6}$ Part-time jobs are relatively prevalent in service occupations, and hence the share of service jobs in U.S. employment is even larger than their share in total labor input. For example, Hecker (2005) reports that service occupations accounted for nearly one in five jobs in 2004 whereas our calculations based on the 2005 American Community Survey find that service occupations contribute approximately one in seven hours of labor input.

${ }^{7}$ Though farm occupations are estimated to have experienced comparable wage growth in this time interval, one should place little weight on these numbers. Census data are unlikely to capture farm earnings accurately in recent decades since a substantial share of U.S. farm labor after 1980 is supplied by illegal immigrants.
} 
Figure 2, alters the above picture of employment polarization considerably. Holding service employment at its 1980 level, the upward twisting of the lower-tail of the employment distribution during the 1990s is largely eliminated. ${ }^{8}$ Moreover, the counterfactual exercise noticeably steepens the relationship between skill level and employment growth in the 1980s, implying that the growth of service occupations partly mitigated the overall decline in lower-tail employment in this decade. Similarly, holding service occupation relative wages (rather than employment) constant at their 1980 level has an analogous though less dramatic dampening effect on wage polarization during the 1990s, essentially eliminating the upward twist of the lower tail in the 1990s. ${ }^{9}$

These facts motivate our inquiry. Because rising employment in service occupations appears central to the twisting of the lower-tail of the wage and employment distributions in the 1990s and forward, we believe that understanding this rise will provide analytic leverage on the phenomenon of wage and employment polarization more generally. The primary hypothesis that we pursue is that the rapid, secular rise in service employment since 1980 is attributable in part to non-neutral changes in productivity among job tasks spurred by advances in information technology. Concretely, this hypothesis stems from the observation that the physical and interpersonal activities performed in service occupations - such as personal care, table-waiting, order-taking, housekeeping, janitorial services - have proven cumbersome and expensive to computerize. The reason, explained succinctly by Pinker (2007, p. 174), is that, "Assessing the layout of the world and guiding a body through it are staggeringly complex engineering tasks, as we see by the absence of dishwashers that can empty themselves or vacuum cleaners that can climb stairs."

This reasoning underlies our theoretical model. A central thrust of recent technological change has been the automation of a large set of 'middle skill' routine cognitive and manual tasks, such as bookkeeping, clerical work and repetitive production tasks (Autor, Levy and Murnane, 2003; ALM, hereafter). These tasks are readily computerized because they follow precise, well-understood procedures. Computerization of routine tasks complements the 'abstract' creative, problem-solving, and

\footnotetext{
${ }^{8}$ The figure is generated using a simple variant of the DiNardo, Fortin and Lemieux (1996) density reweighting method. We pool Census data from either 1990 or 2000 with Census data from 1980 and estimate a weighted logit model for the odds than an observation is drawn from 1980 Census sample (relative to the actual sampling year) using as predictors a service occupation dummy and an intercept. Weights used are the product of Census sampling weights and annual hours of labor supply. We reweight observations in 1990 and 2000 using the estimated odds multiplied by the hours-weighted Census sampling weight. This procedure weights down the frequency of service occupations in 1990 and 2000 to match their 1980 frequency. Given the absence of other covariates in the model, the extra probability mass is implicitly allocated uniformly over the remainder of the distribution.

${ }^{9}$ We fit a weighted OLS regression in each decade of real log hourly wages on a constant and a service occupation dummy using only observations from service occupations, production, craft and repair occupations, and operator, fabricator and laborer occupations, all of which have comparably low education levels. These regressions are weighted by the product of Census sampling weights and annual hours of labor supply (annual weeks worked times average weekly hours). To produce the figure, we adjust service occupation wages in 1990 and 2000 by subtracting off the estimated service occupation premium from the current decade and replacing it with the estimated 1980 service occupation premium.
} 
coordination tasks performed by highly-educated workers (e.g., professionals and managers), for whom data analysis is an input into production. Paradoxically, computerization of routine tasks neither directly substitutes for nor complements the core jobs tasks of numerous low-education occupations, in particular those that rely heavily on physical dexterity and flexible interpersonal communications. We refer to these activities as 'manual tasks.'

Service occupations are disproportionately intensive in manual tasks, as we document below. We hypothesize that the rapid growth of service occupations commencing in the 1980s reflects an interaction between non-neutral technological progress - which raises productivity in routine tasks but does little to augment manual tasks - and consumer preferences. In particular, if consumer preferences do not admit close substitutes for the tangible outputs of service occupations - such as restaurant meals, house-cleaning, security services, and home health assistance - rising output of goods (i.e., non-service activities) spurred by productivity gains will raise aggregate demand for service outputs, and ultimately employment and wages in service occupations.

We explore these implications formally in a simple general equilibrium model of 'routine-task' replacing technological change, building upon ALM (2003), Weiss (2008), and in a broader sense, Baumol's (1967) model of unbalanced growth. ${ }^{10}$ Technological progress in this model takes the form of an ongoing fall in the cost of computerizing routine tasks - which are repetitive tasks performed both by machinery and low-skilled ('non-college') workers in the production of goods. This process complements the high-skilled ('college') workers who perform abstract tasks in goods production but substitutes for low-skilled ('non-college') workers in goods production, who in turn reallocate their labor supply to service occupations, which use exclusively manual tasks and do not experience technological progress.

We use the model to analyze the allocation of labor between goods and services, and the inequality of wages holding constant the supply of high and low-skill workers, as automation drives the price of routine tasks towards zero. A key result is that the limiting behavior of employment and wage inequality hinges critically on the elasticity of substitution between goods and services in consumption. If goods and services are gross substitutes, ongoing technical progress ultimately drives service consumption and service employment to zero. Wage inequality between college and non-college workers rises without bounds as the wages paid to routine tasks are eroded and the productivity of abstract labor is augmented. If, instead, goods and services are weakly complementary, non-college labor will

\footnotetext{
${ }^{10}$ We modify and extend the model of Weiss (2008) to encompass two types of low-skilled labor activities-routine and manual - and to permit self-selection of low-skilled workers among these tasks. These extensions highlight the dynamics of wages and employment of low-skilled workers as they self-select between goods and services sectors in response to ongoing technical change. The limiting cases of our model are qualitatively comparable to Weiss (2008). We thank Matthias Weiss for his input on the model.
} 
be drawn into service occupations as goods output rises. Wages paid to manual tasks - and hence non-college earnings - then ultimately converge to a steady growth rate, which, depending upon the complementarity between goods and services, equals or exceeds the growth rate of college wages. It bears emphasis that this mechanism does not operate through income effects - in fact, consumers in the model have homothetic preferences. The long run positive effect of technical change on service employment and wages results from the interaction between productivity growth that favors goods and preferences that weakly favor services.

Our primary empirical analysis explores the rise of service employment at the level of local labor markets. The identification strategy exploits the fact that the output of service occupations is nonstorable and non-transportable, and hence largely immune to trade and outsourcing. ${ }^{11}$ We measure levels and changes in economic variables over 1980 through 2005 within 722 consistently defined, fully inclusive Commuting Zones using data from the Census Public Use Micro Samples for 1950, 1970, 1980, 1990 and 2000 and from the American Community Survey for 2005.

To isolate potentially exogenous variation in the susceptibility of local labor markets to substitution of information technology for routine labor input, the identification strategy draws on the theoretical model of changing task specialization. We posit that the extent of routine task displacement will depend on the initial concentration of routine job activities within local labor markets, since these jobs are most likely to be automated as the price of computing falls. Using task measures from the Dictionary of Occupational Titles paired with Census data on occupational structure, we generate a simple index measuring the share of labor employed in routine task-intensive occupations in each commuting zone at the start of the relevant time period. ${ }^{12}$

This routine share measure proves strikingly predictive of the changes in employment and wage structure predicted by the model. In commuting zones with an initial concentration in routine-intensive occupations, we find substantially larger growth of employment in service occupations, coupled with differential reallocation of labor input away from routine-intensive occupations. These changes in task allocation occur both in aggregate and within major education groups, with the greatest reductions in routine labor input among non-college workers. Consistent with the model, the rapid reduction of routine employment in initially routine-intensive commuting zones is accompanied by a contemporaneous, differential increase in workplace computer use in these same local labor markets. ${ }^{13}$ The differential

\footnotetext{
${ }^{11}$ Indeed, many service activities—-such as hair cutting, child care, and home health assistance-require physical contact between worker and customer.

${ }^{12}$ Simon (2004) pursues a parallel strategy of relating changes in industrial structure over the course of multiple decades to initial occupational and skill structure.

${ }^{13}$ We use Doms and Lewis' (2006) measure of personal computer penetration at the geographic level. This measure, generously shared by Mark Doms and Ethan Lewis, is also used by Beaudry, Doms and Lewis (2006) to explore the determinants of computer adoption and changes in education returns across metropolitan areas during the period of 1980 through 2000. Their analysis is motivated by a model of endogenous technology adoption, building on Beaudry
} 
growth of service employment in routine-intensive commuting zones is accompanied by a distinct pattern of wage inequality: relative wages rise in both low-skilled service occupations and highly-skilled managerial, professional, technical, sales and administrative occupations; relative wages fall across the remaining set of low-skilled occupations, consistent with a reduction in demand for routine-intensive activities. In summary, these results reveal a process of employment and wage polarization within regional labor markets that parallels the polarization of employment observed in aggregate data.

The recent rise of service employment and accompanying polarization may also have other contributing causes, many of which we explore below. Influential work by Clark (1957) finds that the income elasticity of demand for services is greater than unitary, implying that preferences are nonhomothetic. If so, rising prosperity increases the share of income devoted to services, even with balanced productivity growth. We refer to this as the income-effect hypothesis. A related but distinct hypothesis, explored in papers by Manning (2004), Ngai and Pissarides (2007) and Mazzolari and Ragusa (2008) focuses on substitution rather than income effects. These studies posit that rising returns to skill spur high-skilled workers to substitute market for home-based production of household services, thus increasing their labor supply and earnings while simultaneously raising demand for service jobs. $^{14}$

While these alternative explanations appear both plausible and complementary to our main hypothesis, we stress two key points of differentiation. A first is that our theoretical framework does not rely on either income effects in consumption or substitution effects in labor supply to generate concurrent rises in high and low-skill employment and earnings in general equilibrium. Indeed, consumers in our model have homothetic preferences and do not engage in household production. Second, to the degree that we can empirically test these alternative hypotheses, we find limited support. Growth of service employment within commuting zones is negatively correlated with changes in the hours worked of male and female college graduates, inconsistent with the household substitution hypothesis. Similarly, rising high wages in commuting zones, as measured by growth in the 90th wage percentile, is only weakly correlated with increases in service employment, a pattern that is inconsistent with the income effect hypotheses. Notably, our key explanatory measure, the routine employment share, proves highly robust to controlling for these alternative explanatory variables.

Alongside these demand side determinants of service occupation employment, we also carefully control for a host of other likely contributors, including: rising supply of low-skilled immigrants, which may reduce the market price of services (Cortes, 2008); dwindling manufacturing employment and

and Green (2003), in which geographic variation in computer adoption is driven by the relative abundance or scarcity of skilled workers.

${ }^{14}$ Leonardi (2008) explores the hypothesis that skilled workers demand both more high- and low-skill intensive goods than do unskilled workers. Hence, rising education may cause demand polarization. 
rising unemployment, which may reduce job opportunities for less educated workers (Harrison and Bluestone, 1988); and increases in the educational attainment, elderly population share, and female labor force participation of commuting zone residents. Each of these factors might be expected to contribute to rising employment in service occupations - and indeed, all have the expected correlation with rising penetration of service jobs in local labor markets. Nevertheless, controlling for these factors does not substantially affect the main inference: regions that were initially specialized in routineintensive occupations experienced a disproportionate degree of employment and wage polarization commencing in the 1980s.

In the next section, we outline a model of unbalanced productivity growth and derive implications for trends in labor allocation and wage inequality. Section 3 describes the data sources and details how we measure local labor markets, job tasks and, in particular, routine task-intensity. Sections 4 and 5 present empirical tests of our hypotheses for service employment, task specialization, and wage polarization. Section 6 concludes.

\section{TheORETICAL FRAMEWORK}

Building on work in ALM (2003) and Weiss (2008), this section offers a conceptual model that explores the effects of ongoing, routine task-replacing technological change on three general equilibrium outcomes: the allocation of labor among competing low-skilled activities (in particular, routine versus manual tasks); the scale of service employment; and the inequality of wages between high and low-skill workers.

\subsection{EnVironment}

We consider an economy with two sectors $(j=g, s)$ that produce goods and services for consumption using four factors of production. Three of these factors are labor (task) inputs: manual, routine and abstract $(L=m, r, a)$. These labor inputs are supplied by two types of workers $(i=H, U)$ corresponding to college and non-college workers. The fourth factor of production is computer capital, which is an intermediate (non-consumption) good. In each sector, a continuum of mass one of firms produces output.

Production of goods combines routine labor, abstract labor, and computer capital $(K)$, measured in efficiency units, using the following technology:

$$
Y_{g}=L_{a}^{1-\beta}\left[(1-\lambda)\left(\alpha_{r} L_{r}\right)^{\mu}+\lambda\left(\alpha_{k} K\right)^{\mu}\right]^{\beta / \mu},
$$

with $\beta, \mu \in(0,1)$. In this production function, the elasticity of substitution between abstract labor and the routine task input is 1 while the elasticity of substitution between routine labor and computer 
capital is $\sigma_{r}=1 /(1-\mu)$ and, by assumption, is greater than 1. By implication, $K$ is a relative complement to abstract labor and a relative substitute for routine labor. ${ }^{15}$

The second sector, which produces services, uses only manual labor, measured in efficiency units as $L_{m}$ :

$$
Y_{s}=\alpha_{s} L_{m}
$$

where $\alpha_{s}>0$ is an efficiency parameter. We will normalize $\alpha_{s}$ to 1 in the rest of the paper, and so $\alpha_{r}$ may be thought of as a relative efficiency term.

There is a continuum of mass one of high-skilled workers, $H$, who are fully specialized in abstract labor. Each $H$ worker supplies abstract labor inelastically to the goods sector.

There is a continuum of mass one of low-skilled workers, $U$, each of whom supplies either manual or routine labor. Low-skill workers have homogeneous skill at performing manual tasks. If all $U$ workers were to perform manual tasks, they would supply a unit mass of manual labor.

Low-skilled workers have heterogeneous skills in performing routine tasks. Let $\eta$ equal a worker's skill in routine tasks, measured in efficiency units, with density and distribution functions $f(\eta)$ and $F(\eta)$. There is a mass of one of potential routine labor input: $\int \eta f(\eta) d \eta=1$. Each worker of type $U$ supplies labor inelastically to the task offering the highest income level given her endowment, $\eta$.

It is convenient to choose a functional form for $f(\eta)$ to permit analytic solutions of the model. The choice of functional form is innocuous, however, since the long run equilibrium of the model (i.e., as $t \rightarrow \infty$ ) depends on technology and preferences, not on labor supply per se. Let $\eta$ be distributed exponentially on the interval $[0, \infty]$ with $f(\eta)=e^{-\eta}$.

Computer capital, $K$, is produced and competitively supplied using the following technology:

$$
K=Y_{k}(t) e^{\delta t} / \theta
$$

where $Y_{k}(t)$ is the amount of the final consumption good allocated to production of $K, \delta>0$ is a positive constant, and $\theta=e^{\delta}$ is an efficiency parameter. Productivity is rising at $\delta$, reflecting technological progress. At time 1, one unit of the consumption good $Y$ can be used to produce one efficiency unit of computer capital:

$$
1=e^{\delta} / \theta
$$

Competition will guarantee that the real price of computer capital (measured in efficiency units) is equal to marginal (and average) cost. So, at time $t=1, p_{k}=1$. As time advances, this price falls, with

$$
p_{k}=\frac{Y_{k}}{K}=\theta e^{-\delta t}
$$

\footnotetext{
${ }^{15}$ In the Theory Appendix, we also consider the case where $\mu<0$ and so $L_{r}$ and $K$ are gross complements.
} 
To close the model, we model all consumers/workers as having identical CES utility functions defined over consumption of goods and services:

$$
\begin{aligned}
u & =\left(c_{s}^{\rho}+c_{g}^{\rho}\right)^{1 / \rho}, \\
\text { where } \rho & <1 .
\end{aligned}
$$

The elasticity of substitution in consumption between goods and services is $\sigma_{c}=1 /(1-\rho)$. Consumers hold equal shares of all firms.

Consumers take prices and wages as given and maximize utility subject to the budget constraint that wages equal consumption. Firms maximize profits taking the price of consumption goods and wages as given. The CRS technology insures that equilibrium profits will be zero.

Of interest in this model is the long-run (as $t \rightarrow \infty$ ) allocation of low-skilled labor to goods and services, and the evolution of inequality, measured by the manual to abstract and manual to routine wage ratios. We next derive the static solution of the model and its asymptotic equilibrium. Section (2.7) summarizes the model's solution and empirical implications.

\subsection{Equilibrium}

We normalize the price of good $g$ to 1 , i.e. $p_{g}(t)=1$ for all $t$, without loss of generality. We can define the equilibrium as follows.

Definition 1 An equilibrium in this economy is a tuple of aggregate allocations and prices $\left(Y_{s}(t), Y_{g}(t), C_{s}(t)\right.$, and a cutoff skill for unskilled workers $\eta^{*}(t)$ such that

1. The representative consumer maximizes (6) subject to the budget constraint

$$
C_{g}(t)+C_{s}(t) p_{s}(t) \leq L_{a}(t) w_{a}(t)+L_{m}(t) w_{m}(t)+L_{r}(t) w_{r}(t)
$$

2. The firms that produce services and goods maximize profits, that is

$$
\begin{aligned}
& w_{m}(t)=\alpha_{s} p_{s}(t) \\
& w_{a}(t)=\frac{d\left(L_{a}(t)^{1-\beta}\left[(1-\lambda)\left(\alpha_{r} L_{r}(t)\right)^{\mu}+\lambda\left(\alpha_{k} K(t)\right)^{\mu}\right]^{\beta / \mu}\right)}{d L_{a}(t)} \\
& w_{r}(t)=\frac{d\left(L_{a}(t)^{1-\beta}\left[(1-\lambda)\left(\alpha_{r} L_{r}(t)\right)^{\mu}+\lambda\left(\alpha_{k} K(t)\right)^{\mu}\right]^{\beta / \mu}\right)}{d L_{r}(t)} \\
& w_{k}(t)=\frac{d\left(L_{a}(t)^{1-\beta}\left[(1-\lambda)\left(\alpha_{r} L_{r}(t)\right)^{\mu}+\lambda\left(\alpha_{k} K(t)\right)^{\mu}\right]^{\beta / \mu}\right)}{d K(t)}
\end{aligned}
$$


The firms that can convert output goods to capital goods (within the period) maximize profits, that is

$$
w_{k}(t) \leq \theta e^{-\delta t} \text { (with equality if } K(t)>0 \text { ) }
$$

The unskilled workers allocate their labor between routine and manual tasks optimally, that is

$$
w_{m}(t)\left\{\begin{array}{c}
\geq \eta^{*}(t) w_{r}(t) \text { if } L_{m}(t)=1 \\
=\eta^{*}(t) w_{r}(t) \text { if } L_{m}(t) \in(0,1) \\
\leq \eta^{*}(t) w_{r}(t) \text { if } L_{m}(t)=0
\end{array}\right.
$$

3. Labor and goods markets clear, that is

$$
\begin{aligned}
L_{a}(t) & =1 \\
L_{m}(t) & =\int_{0}^{\eta^{*}} e^{-\eta} d \eta=1-e^{-\eta^{*}} \\
L_{r}(t) & =\int_{\eta^{*}}^{1} \eta e^{-\eta} d \eta=\left(\eta^{*}+1\right) e^{-\eta^{*}} \\
C_{s}(t) & =Y_{s}(t)=\alpha_{s} L_{m}(t) \\
C_{g}(t)+K(t) \theta e^{-\delta t} & =Y_{g}(t) .
\end{aligned}
$$

\subsection{Capital demand}

First note that there are no dynamic linkages, hence the equilibrium at each $t$ can be separately characterized given the level of productivity $\theta e^{-\delta t}$.

We claim that the choice of capital in this economy solves

$$
\max _{K(t) \in \mathbb{R}_{+}} L_{a}(t)^{1-\beta}\left[(1-\lambda)\left(\alpha_{r} L_{r}(t)\right)^{\mu}+\lambda\left(\alpha_{k} K(t)\right)^{\mu}\right]^{\beta / \mu}-\theta e^{-\delta t} K(t) .
$$

This can be seen by combining equations (11) and (12) and noting that the choice of capital satisfies the

first order condition for the above concave maximization problem. Note that, by the market clearing condition (16), the objective function for Problem (17) is equal to $C_{g}$. Therefore, the choice of capital in equilibrium maximizes net output in the economy (which is consumed by the representative agent). We denote the optimal value of Problem (17) $F\left(L_{a}(t), L_{r}(t), t\right)$. We have that $F\left(L_{a}(t), L_{r}(t), t\right)$ is strictly increasing and differentiable in $L_{a}(t)$ and $L_{r}(t)$ with derivatives

$$
\begin{aligned}
& w_{r}=\frac{d F\left(L_{a}(t), L_{r}(t), t\right)}{d L_{r}(t)} \\
& w_{a}=\frac{d F\left(L_{a}(t), L_{r}(t), t\right)}{d L_{a}(t)}
\end{aligned}
$$

where the equivalence with wages $w_{r}$ and $w_{a}$ comes from the equilibrium conditions (10) and (9) along with the envelope theorem for Problem (17). We will not explicitly solve for $F$ since the exact 
algebraic expression is cumbersome. Instead we will derive its asymptotic properties (sufficient for our analysis) for each of the cases we analyze below.

\subsection{Demand for manual Labor}

We next derive a demand and a supply curve for $L_{m}(t)$ given price $p_{s}$, which will characterize the static equilibrium. The consumer optimization implies

$$
p_{s}=\left(\frac{L_{m}(t)}{F\left(1, L_{r}(t), t\right)}\right)^{-1 / \sigma_{c}} .
$$

Note that, given the cutoff $\eta^{*}(t)$, we have that $L_{m}(t)$ and $L_{r}(t)$ are given by Equations. (14) and (15), hence they are related with

$$
\begin{aligned}
L_{r}(t) & =\left(1-\log \left(1-L_{m}(t)\right)\right)\left(1-L_{m}(t)\right) \\
& \equiv g\left(L_{m}(t)\right)
\end{aligned}
$$

where $g:[0,1] \rightarrow[0,1]$ is a strictly decreasing function with $g(0)=1$ and $g(1)=0$. Plugging this in Eq.(20) gives

$$
p_{s}=\left(\frac{F\left(1, g\left(L_{m}(t)\right), t\right)}{L_{m}(t)}\right)^{1 / \sigma_{c}},
$$

which gives a demand equation for $L_{m}(t)$. Note that $F$ is strictly increasing in the second variable and $g$ is strictly decreasing, so the demand curve is strictly decreasing. Note that the demand curve starts from $p_{s}\left(L_{m}=0\right)=\infty$ and goes down to $p_{s}\left(L_{m}=1\right)=(F(1,0, t))^{1 / \sigma_{c}}$ (which is 0 when $\mu<0$, but may be positive when $\mu>0)$.

\subsection{Supply of manual Labor}

To derive a supply equation for $L_{m}(t)$, we use Equations. (8) and (18) in the equation

$$
w_{m}(t)=\eta^{*}(t) w_{r}(t) .
$$

to get

$$
p_{s}(t)=\eta^{*}(t) \frac{d F\left(1, L_{r}(t), t\right)}{d L_{r}(t)} .
$$

Plugging in $L_{r}(t)=g\left(L_{m}(t)\right)$ and also

$$
\eta^{*}(t)=\eta\left(L_{m}\right) \equiv-\log \left(1-L_{m}(t)\right),
$$

we have

$$
p_{s}(t)=-\log \left(1-L_{m}(t)\right) \frac{d F\left(1, g\left(L_{m}(t)\right), t\right)}{d L_{r}(t)} .
$$


The supply equation will typically be increasing, but it may not be increasing everywhere. It starts from $p_{s}\left(L_{m}=0\right)=0$ and limits to $p_{s}\left(L_{m}=1\right)=\infty$ hence the supply and demand curves always intersect.

Putting the demand and supply equations together, we have

$$
F\left(1, g\left(L_{m}(t)\right), t\right)^{1 / \sigma_{c}}=-L_{m}(t)^{1 / \sigma_{c}} \log \left(1-L_{m}(t)\right) \frac{d F\left(1, g\left(L_{m}(t)\right), t\right)}{d L_{r}(t)} .
$$

which characterizes the equilibrium value of $L_{m}(t)$. The following proposition shows that an equilibrium always exists.

Proposition 1 An equilibrium exists. The equilibrium level of $L_{m}(t)$ is characterized as the solution to Eq. (24). Once $L_{m}(t)$ is determined, the remaining variables are determined from the equilibrium conditions in Definition 1.

Typically, there will be a unique intersection for supply and demand curves and we will be able to analyze the dynamics (as technology progresses) by looking at how the intersection point moves. We will study the dynamics in a simulation. Next, we will analyze the limiting behavior of this economy as $t \rightarrow \infty$.

\subsection{Asymptotic Equilibrium}

Assume (it is easy to verify this assumption) that $L_{m}(t)$ asymptotes to a constant in the limit, $\lim _{t \rightarrow \infty} L_{m}(t)=L_{m}^{*}$. Note that the Theorem of the Maximum applied to Problem (17) implies that the optimum level of $K(t)$ is increasing in $t$. Moreover, at $t=\infty$, cost of capital would be zero and $K=\infty$ would be optimal, hence optimal $K(t)$ will be arbitrarily large for sufficiently large $t$, i.e., we have $\lim _{t \rightarrow \infty} K(t)=\infty$. To make progress for solving Eq. (24) in the limit, we need to evaluate the limit values for $F\left(1, g\left(L_{m}(t)\right), t\right)$ and $\frac{d F\left(1, g\left(L_{m}(t)\right), t\right)}{d L_{r}(t)}$.

\subsubsection{Capital input}

Rewrite Problem (17) as

$$
\max _{K(t) \in \mathbb{R}_{+}} \lambda^{\beta / \mu}\left(\alpha_{k} K(t)\right)^{\beta} \frac{\left[(1-\lambda)\left(\alpha_{r} L_{r}(t)\right)^{\mu}+\lambda\left(\alpha_{k} K(t)\right)^{\mu}\right]^{\beta / \mu}}{\lambda^{\beta / \mu}\left(\alpha_{k} K(t)\right)^{\beta}}-\theta e^{-\delta t} K(t) .
$$


Note that the term $\frac{\left[(1-\lambda)\left(\alpha_{r} L_{r}(t)\right)^{\mu}+\lambda\left(\alpha_{k} K(t)\right)^{\mu}\right]^{\beta / \mu}}{\lambda^{\mu / \beta}\left(\alpha_{k} K(t)\right)^{\beta}} \downarrow 1$ as $K(t) \rightarrow \infty$. This suggests that we introduce another maximization problem

$$
G(1, t)=\max _{K(t)} \lambda^{\beta / \mu}\left(\alpha_{k} K(t)\right)^{\beta}-\theta e^{-\delta t} K(t),
$$

and denote its solution by $\tilde{K}(t)$. We claim that, in the limit, the value and the optimal solution to this maximization problem behaves like those of the optimization problem in (25). More specifically, we claim

$$
\lim _{t \rightarrow \infty} \frac{F\left(1, g\left(L_{m}(t)\right), t\right)}{G(1, t)}=1 \text { and } \lim _{t \rightarrow \infty} \frac{K(t)}{\tilde{K}(t)}=1
$$

To prove this statement formally, consider the first order condition for Problem (25)

$$
\beta \lambda \alpha_{k}^{\mu} K(t)^{\mu-1}\left[(1-\lambda)\left(\alpha_{r} L_{r}(t)\right)^{\mu}+\lambda\left(\alpha_{k} K(t)\right)^{\mu}\right]^{(\beta-\mu) / \mu}=\theta e^{-\delta t} .
$$

Similarly, consider the first order condition for Problem (26)

$$
\beta \lambda^{\beta / \mu} \alpha_{k}^{\beta} \tilde{K}(t)^{\beta-1}=\theta e^{-\delta t}
$$

Dividing the last two displayed equations, taking the limit and noting that $K(t) \rightarrow \infty$ proves our claim in Eq. (27). Note that by straightforward algebra, $G(1, t)$ and $\tilde{K}(t)$ can be calculated as

$$
\tilde{K}(t)=\left(\lambda^{\mu / \beta}\left(\alpha_{k}\right)^{\beta} \frac{e^{\delta t}}{\theta}\right)^{1 /(1-\beta)} \text { and } G(1, t)=(1-\beta) \lambda^{\mu / \beta} \alpha_{k}^{\beta} \tilde{K}(t)^{\beta} .
$$

Combining the last equation and Eq. (27), we have

$$
\lim _{t \rightarrow \infty} \frac{F\left(1, g\left(L_{m}(t)\right), t\right)}{c_{1} K(t)^{\beta}}=1,
$$

where $c_{1} \equiv(1-\beta) \lambda^{\mu / \beta} \alpha_{k}^{\beta}$ is some constant. Eq. (28) characterizes the behavior of $F$ in the limit. In words, in the limit, routine labor become less and less important in production (since $\mu>0$ ) and $F$ behaves as a production function that does not use routine labor at all.

Next, we consider $\frac{d F\left(1, g\left(L_{m}(t)\right), t\right)}{d L_{r}(t)}$. Since $K(t) \rightarrow \infty$, we have

$$
\begin{aligned}
& \lim _{t \rightarrow \infty} \frac{\frac{d F\left(1, g\left(L_{m}(t)\right), t\right)}{d L_{r}(t)}}{\beta(1-\lambda) \alpha_{r}^{\mu} \lambda^{(\beta-\mu) / \mu} L_{r}(t)^{\mu-1}\left(\alpha_{k} K(t)\right)^{(\beta-\mu)}} \\
= & \lim _{t \rightarrow \infty} \frac{\beta(1-\lambda) \alpha_{r}^{\mu} L_{r}(t)^{\mu-1}\left[(1-\lambda)\left(\alpha_{r} L_{r}(t)\right)^{\mu}+\lambda\left(\alpha_{k} K(t)\right)^{\mu}\right]^{(\beta-\mu) / \mu}}{\beta(1-\lambda) \alpha_{r}^{\mu} \lambda^{(\beta-\mu) / \mu} L_{r}(t)^{\mu-1}\left(\alpha_{k} K(t)\right)^{(\beta-\mu)}} \\
= & 1,
\end{aligned}
$$

where the first line uses the expression in (46) and the last line uses the fact that $\lim _{t \rightarrow \infty} K(t)=\infty$. 
Hence we have

$$
\lim _{t \rightarrow \infty} \frac{\frac{d F\left(1, g\left(L_{m}(t)\right), t\right)}{d L_{r}(t)}}{c_{2} g\left(L_{m}(t)\right)^{\mu-1} K(t)^{\beta-\mu}}=1,
$$

where $c_{2} \equiv \beta(1-\lambda) \alpha_{r}^{\mu} \lambda^{(\beta-\mu) / \mu} \alpha_{k}^{\beta-\mu}$ is some constant and we have used $L_{r}(t)=g\left(L_{m}(t)\right)$. This characterizes the limiting behavior for $\frac{d F\left(1, g\left(L_{m}(t)\right), t\right)}{d L_{r}(t)}$.

\subsubsection{LABOR SUPPLY ASYMPTOTICS}

We now use Equations. (28) and (29) in Eq. (24) to solve for the asymptotic equilibrium level of $L_{m}(t)$. We can rewrite Eq. (24) as

$$
\begin{aligned}
& {\left[\frac{F\left(1, g\left(L_{m}(t)\right), t\right)}{c_{1} K(t)^{\beta /(1-\beta)}}\right]^{1 / \sigma_{c}} c_{1}^{1 / \sigma_{c}} K(t)^{\beta / \sigma_{c}} } \\
= & -L_{m}(t)^{1 / \sigma_{c}} \log \left(1-L_{m}(t)\right) c_{2} K(t)^{\beta-\mu} g\left(L_{m}(t)\right)^{\mu-1}\left[\frac{\frac{d F\left(1, g\left(L_{m}(t)\right), t\right)}{d L_{r}(t)}}{c_{2} g\left(L_{m}(t)\right)^{\mu-1} K(t)^{\beta-\mu}}\right]
\end{aligned}
$$

which, with some algebra and using Eq. (21), can be simplified to

$$
\begin{aligned}
& \frac{c_{1}^{1 / \sigma_{c}}}{c_{2}} \frac{\left[\frac{F\left(1, g\left(L_{m}(t)\right), t\right)}{c_{1} K(t)^{\beta /(1-\beta)}}\right]^{1 / \sigma_{c}}}{\left[\frac{\frac{d F\left(1, g\left(L_{m}(t)\right), t\right)}{d L_{r}(t)}}{c_{2} g\left(L_{m}(t)\right)^{\mu-1} K(t)^{\beta-\mu}}\right]} K(t)^{\beta / \sigma_{c}-(\beta-\mu)} \\
= & -\log \left(1-L_{m}(t)\right) L_{m}(t)^{1 / \sigma_{c}}\left(1-\log \left(1-L_{m}(t)\right)\right)^{\mu-1}\left(1-L_{m}(t)\right)^{\mu-1} .
\end{aligned}
$$

When we take the limit as $t \rightarrow \infty$, the terms in brackets go to 1 , hence

$$
\begin{aligned}
& \frac{c_{1}^{1 / \sigma_{c}}}{c_{2}} \lim _{t \rightarrow \infty} K(t)^{\beta / \sigma_{c}-(\beta-\mu)} \\
= & \lim _{t \rightarrow \infty}-\log \left(1-L_{m}(t)\right) L_{m}(t)^{1 / \sigma_{c}}\left(1-\log \left(1-L_{m}(t)\right)\right)^{\mu-1}\left(1-L_{m}(t)\right)^{\mu-1} .
\end{aligned}
$$

Since $K(t) \rightarrow \infty$, the left hand side either goes to 0 or $\infty$ depending on the sign of $\beta / \sigma_{c}-(\beta-\mu)$. The right hand side goes to 0 if $L_{m}(t) \rightarrow 0$, and to $\infty$ if $L_{m}(t) \rightarrow 1 .^{16}$ Hence, the fact that the

\footnotetext{
${ }^{16}$ Proving that the RHS limits to $\infty$ as $L_{m}(t) \rightarrow 1$ requires some careful algebra. First, note that as $L_{m}(t) \rightarrow 1$ $\lim _{t \rightarrow \infty} \frac{\left(1-\log \left(1-L_{m}(t)\right)\right)^{\mu-1}}{-\log \left(1-L_{m}(t)\right)^{\mu-1}}=1$. Then, in this case the RHS limit can be rewritten as

$$
\left(-\log \left(1-L_{m}(t)\right)\right)^{\mu} L_{m}(t)^{1 / \sigma_{c}}\left(1-L_{m}(t)\right)^{\mu-1}
$$

Recall that we are analyzing the case $\mu>0$. Hence the first term in this expression goes to $\infty$ at an exponential rate. If $\mu<1$, then the last term goes to $\infty$ as well and the limit is $\infty$ as claimed. Else if $\mu>1$, the last term goes to 0 , but it goes to zero at a polynomial rate. Since the first term goes to $\infty$ at an exponential rate and the last term goes to zero at a polynomial rate, the product goes to $\infty$ as claimed. This step can more rigorously be proven using the L'Hôpital's Rule.
} 
equality above holds in the limit implies

$$
\lim _{t \rightarrow \infty} L_{m}(t)=\left\{\begin{array}{l}
0 \text { if } \frac{1}{\sigma_{c}}<\frac{\beta-\mu}{\beta} \\
1 \text { if } \frac{1}{\sigma_{c}}>\frac{\beta-\mu}{\beta} .
\end{array} .\right.
$$

In words, if the share of machines in goods production is sufficiently small $(\beta<\mu)$ or if goods and

services are sufficiently complementary $\left(\frac{1}{\sigma_{c}}>\frac{\beta-\mu}{\beta}\right)$, then then in the limit all unskilled labor is drawn to manual tasks. Else if $\beta>\mu$ and $\frac{1}{\sigma_{c}}<\frac{\beta-\mu}{\beta}$, that is, the share of machine in goods production is large and goods and services are sufficiently substitutable, then routine tasks continue to be important in the limit and all labor is drawn to routine tasks.

\subsubsection{Wage inequality asymptotics}

We calculate the limiting behavior for abstract, manual and routine wages. For manual wages, we have

$$
w_{m}(t)=p_{s}(t)=\left(\frac{F\left(1, g\left(L_{m}(t)\right), t\right)}{L_{m}(t)}\right)^{1 / \sigma_{c}},
$$

where we have used the demand equation. Hence, using Eq. (28), we have

$$
\lim _{t \rightarrow \infty} \frac{w_{m}(t)}{c_{1}^{1 / \sigma_{c}}\left(K(t)^{\beta} / L_{m}(t)\right)^{1 / \sigma_{c}}}=1
$$

For abstract wages, we have

$$
w_{a}(t)=\frac{d F\left(1, g\left(L_{m}(t)\right), t\right)}{d L_{a}(t)}=(1-\beta) F\left(1, g\left(L_{m}(t)\right), t\right),
$$

hence using Eq. (28), we have

$$
\lim _{t \rightarrow \infty} \frac{w_{a}(t)}{(1-\beta) c_{1} K(t)^{\beta}}=1
$$

Now using the fact that

$$
w_{m}(t)=w_{r}(t) \eta\left(L_{m}\right)
$$

in equilibrium, we also derive the limiting behavior for routine wages as

$$
\lim _{t \rightarrow \infty} \frac{w_{r}(t)}{c_{1}^{1 / \sigma_{c}} K(t)^{\beta / \sigma_{c}} /\left[L_{m}(t)^{1 / \sigma_{c}} \times-\log \left(1-L_{m}\right)\right]}=1 .
$$

We are also interested in relative wages. From $w_{m}(t)=w_{r}(t) \eta\left(L_{m}\right)$, we clearly have

$$
\frac{w_{m}(t)}{w_{r}(t)}=\eta\left(L_{m}\right)=\left\{\begin{aligned}
0 & \text { if } \frac{1}{\sigma_{c}}<\frac{\beta-\mu}{\beta} \\
\infty & \text { if } \frac{1}{\sigma_{c}}>\frac{\beta-\mu}{\beta} .
\end{aligned}\right.
$$


Also, from Equations.(32) and (33), we have

$$
\lim _{t \rightarrow \infty} \frac{w_{a}(t)}{w_{m}(t)}=\lim _{t \rightarrow \infty} \frac{(1-\beta) c_{1} K(t)^{\beta}}{c_{1}^{1 / \sigma_{c}}\left(K(t)^{\beta} / L_{m}(t)\right)^{1 / \sigma_{c}}}=\left\{\begin{array}{c}
\infty \text { if } \sigma_{c}>1 \\
(1-\beta) \text { if } \sigma_{c}=1 \\
0 \text { if } \sigma_{c}<1
\end{array}\right.
$$

Hence, we summarize our findings for wages and relative wages in this case $(\mu>0)$ as follows. We have that wages for manual and abstract labor always go to infinity. The relative wage of manual labor to routine labor $w_{m}(t) / w_{r}(t)$ go to infinity if $\frac{1}{\sigma_{c}}>\frac{\beta-\mu}{\beta}$ and to zero otherwise (which is, not surprisingly, the same condition which determines the limiting value of $\left.L_{m}(t)\right)$. Finally, relative wages for abstract to manual labor depend on $\sigma_{c}$ : If $\sigma_{c}<1$, then $w_{a}(t) / w_{m}(t)$ is 0 ; if $\sigma_{c}=1$, then $w_{a}(t) / w_{m}(t)$ is $(1-\beta)$, and if $\sigma_{c}<1$, then $w_{a}(t) / w_{m}(t)$ is 0 . We summarize our findings in the following proposition.

Proposition 2 When $\mu>0$, we have $L_{m}(t) \rightarrow 1$ if $\frac{1}{\sigma_{c}}>\frac{\beta-\mu}{\beta}$ and $L_{m}(t) \rightarrow 0$ if $\frac{1}{\sigma_{c}}<\frac{\beta-\mu}{\beta}$. For the limit wages, we have

$$
\begin{aligned}
& \lim _{t \rightarrow \infty} \frac{w_{m}(t)}{w_{r}(t)}=\left\{\begin{array}{l}
\infty \text { if } \frac{1}{\sigma_{c}}>\frac{\beta-\mu}{\beta} \\
0 \text { if } \frac{1}{\sigma_{c}}<\frac{\beta-\mu}{\beta}
\end{array}\right. \\
& \lim _{t \rightarrow \infty} \frac{w_{a}(t)}{w_{r}(t)}=\infty \\
& \lim _{t \rightarrow \infty} \frac{w_{a}(t)}{w_{m}(t)}=\left\{\begin{array}{c}
0 \text { if } \sigma_{c}<1, \\
\infty \text { otherwise. }
\end{array}\right.
\end{aligned}
$$

\subsection{Summary AND EMPIRICAL IMPLICATIONS}

In summary, the ongoing substitution of computer capital for routine labor input in our modeldriven by the falling price of computer power - spurs low-skilled workers to reallocate labor input from routine tasks in goods production to manual tasks in the production of services. Employment and wages in middle-skill clerical and routine production jobs declines. Employment in low-skill service occupations rises. Wage inequality rises between high and middle-skill workers rises due to the combination of rising productivity of abstract tasks and a falling price of routine tasks. Inequality between high and low-skill workers may ultimately converge to a steady state, or may expand indefinitely. ${ }^{17}$ In particular:

1. When the share of routine tasks in goods production is sufficiently small $(\beta<\mu)$ or the elasticity

\footnotetext{
${ }^{17}$ Numerical simulations of the model show that if goods and services are complements, the time path of wage inequality may be non-monotone. Service output grows and service wages fall as low-skilled workers initially reallocate labor from goods to services - thus, from routine to manual tasks. When labor flows to services stabilize, low-skilled wages rise. Consequently, wage inequality between high and low-skilled workers may initially increase then plateau or fall. A set of figures from this simulation is available from the authors.
} 
of substitution between goods and services is sufficiently small $\left(1 / \sigma_{c}>[(\beta-\mu) / \beta]\right)$, then all unskilled labor gets allocated to manual tasks, and the wage of routine labor relative to manual labor goes to zero.

2. When the share of routine tasks in goods production is sufficiently large $(\beta>\mu)$ and the elasticity of substitution between goods and services is sufficiently large $\left(1 / \sigma_{c}<[(\beta-\mu) / \beta]\right)$, then all unskilled labor is allocated to routine tasks in the limit. The ratio of manual wage to routine wage limits to zero. The ratio of abstract wage to routine wage in this case always limits to infinity (since we necessarily have $\sigma_{c}>1$ ). Hence, in the limit, the abstract wage is greater than the routine wage which is in turn greater than the manual wage.

3. The relative wage of abstract to manual labor limits to infinity if $\sigma_{c}>1$, to zero if $\sigma_{c}<1$, and to $1-\beta$ if $\sigma_{c}=1$.

One element of realism intentionally omitted from the model is the potential endogeneity of the supply of skilled labor. In reality, changes in earnings inequality will alter the path of skills accumulation, thus preventing wage inequality from either rising without bound or collapsing. ${ }^{18}$ We omit this from the model to emphasize that even with human capital stocks held constant, ongoing skilled-labor augmenting technical change need not imply ongoing growth of inequality.

Can this aggregate model be applied to the analysis of employment and wages in detailed geographic areas, such as cities or commuting zones? The answer depends on whether these areas can plausibly be treated as approximating separate markets. If yes, the model predicts that markets with higher initial concentration in routine tasks - corresponding to higher values of $\beta$ in local goods production - will see greater growth of service employment and greater polarization of wages as computerization progresses. ${ }^{19}$ If no, we must consider to what extent the model applies in local labor markets that interact in a full spatial equilibrium.

There is one key factor that aids the identification of the model in the more general, spatial equilibrium case: the output of service occupations is non-traded, and hence inter-region trade is not expected to enforce a uniform service wage across geographic areas. In the short run, local demand shocks should therefore affect local service occupation wage levels. The rate at which these regional wage differences are arbitraged over the longer run depends upon the responsiveness of labor movements to cross-region wage variation. Much evidence suggests that mobility responses to labor

\footnotetext{
${ }^{18}$ Indeed, in our data, the non-college share of worked hours falls from 58 to 38 percent between 1980 and 2005.

${ }^{19}$ Formally, we could rewrite equation (1) at the city (or commuting zone) level with a city-specific routine task intensity: $y_{j g}=\alpha_{g} R^{b_{j}} A^{1-b_{j}}$ where $j$ denotes cities and a higher value of $b_{j}$ indicates greater initial routine task intensity. If all other preference and labor supply parameters are comparable across cities (that is, uncorrelated with $b_{j}$ ), a uniform decline in the routine task price that is common across cities will induce greater growth in wage inequality and service employment in high $b$ cities.
} 
demand shocks across US cities and states are typically slow and incomplete (Topel, 1986; Blanchard and Katz, 1992; Glaeser and Gyourko, 2005). Mobility is particularly low for the less-educated, who comprise the majority of service occupation workers (Bound and Holzer, 2000). It is therefore plausible that local demand shocks may affect service wages even over the medium term.

In addition, the non-tradability of service outputs has a second useful implication: because demanders and suppliers of service occupations must collocate, the geographic analysis can potentially identify the local determinants of the demand for service jobs, even in the case when service wage levels are not set locally. Consequently, we expect the 'quantity' implications of the theoretical framework to hold at the local labor market level, even in full spatial equilibrium. The wage side of the analysis must be treated as more speculative.

\section{Data sources and measurement}

We provide key details on data construction and measurement in this section, with many further details of our sample construction, geographic matching and occupational classification scheme provided in the Data Appendix.

\subsection{Data SOURCES}

Large sample sizes are essential for an analysis of changes in labor market composition at the detailed geographic level. Our analysis draws on the Census Integrated Public Use Micro Samples (Ruggles et al. 2004) for the years 1950, 1970, 1980, 1990, and 2000 and the American Community Survey (ACS) for 2005. ${ }^{20}$ The Census samples for 1980, 1990 and 2000 include 5 percent of the U.S. population, the 1970 Census and ACS sample include 1 percent of the population, and the 1950 Census sample includes approximately 0.2 percent of the population. ${ }^{21}$

Our analysis also requires a time-consistent definition of local labor markets. Previous research has often used Metropolitan Statistical Areas (MSAs) as a proxy for local labor markets (e.g., Beaudry, Doms, and Lewis 2006). MSAs are defined by the U.S. Office for Management and Budget for statistical purposes; they consist of a large population nucleus and adjacent communities that have a high degree of social and economic integration with the core city. The geographic definition of MSAs is periodically adjusted to reflect the growth of cities. Despite efforts to improve the time-consistency of MSA definitions (e.g., Jaeger et al. 1998), the information provided by the Census Public Use Micro Samples does not allow for a consistent measurement of MSAs. This lack of geographic consistency is problematic for an analysis of changes in employment composition. Of particular concern is that

\footnotetext{
${ }^{20}$ Comparable detailed geographic information is not available in the 1960 Census.

${ }^{21}$ The 1950 sample-line subsample on which we rely is only one-fifth as large as the full 1 percent public use sample. We use the sample-line file because it contains education and occupation variables, which are key to our analysis.
} 
the employment characteristics of the suburban areas that are gradually added to MSAs are likely to systematically differ from the characteristics of the core cities. In addition, MSAs do not cover the rural parts of the US.

We pursue an alternative approach to defining local labor markets based on the concept of Commuting Zones (CZs), developed by Tolbert and Sizer (1996), who used county-level commuting data from the 1990 Census data to create 741 clusters of counties that are characterized by strong commuting ties within CZs, and weak commuting ties across CZs. ${ }^{22}$ Our analysis focuses on the $722 \mathrm{CZs}$ that cover the entire mainland of the US, including both metropolitan and rural areas. Relative to other geographic units used for analysis of local labor markets, commuting zones have two advantages: they are based primarily on economic geography rather than incidental factors such as minimum population or state boundaries; and they cover the entire US. In addition, it is possible to use Census Public Use Micro Areas (PUMAs) to consistently match Census geography to CZs for the full period of our analysis. We are not aware of prior economic research that makes use of this geographic construct.

\subsection{Measuring the 'Routine employment Share'}

A crucial input into our analysis is a summary index of routine task activities within commuting zones. We compute this information from the occupational composition of employment. We measure routine task-intensity in each occupation using data from ALM (2003), who merge job task requirements - manual, routine and abstract - from the fourth edition of the US Department of Labor's Dictionary of Occupational Titles (US Department of Labor, 1977; 'DOT' hereafter) to their corresponding Census occupation classifications. ${ }^{23}$ For each occupation $k$, we form an index of routine task-intensity, $R T I$ :

$$
R T I_{k}=\ln \left(\hat{R}_{k, 1980} / \hat{M}_{k, 1980}\right)
$$

where $\hat{R}$ and $\hat{M}$ are, respectively, the intensity of routine and manual task input in each occupation in 1980, measured on a 0 to 10 scale. $^{24}$ This measure is rising in the relative importance of routine tasks within an occupation and falling in the relative importance of manual tasks. Since RTI does not

\footnotetext{
${ }^{22}$ Tolbert and Killian (1987) earlier developed commuting zones using the 1980 Census. These commuting zones are largely but not fully identical with the 1990 definitions.

${ }^{23}$ Following Autor, Katz and Kearney (2006), we collapse ALM's original five task measures to three task aggregates: the manual task index corresponds to the DOT variable measuring an occupation's demand for "eye-hand-foot coordination;" the routine task measure is a simple average of two DOT variables, "set limits, tolerances and standards," measuring an occupation's demand for routine cognitive tasks, and "finger dexterity," measuring an occupation's use of routine motor tasks; and the abstract task measure is the average of two DOT variables: "direction control and planning," measuring managerial and interactive tasks, and "GED Math," measuring mathematical and formal reasoning requirements. Further details on these variables are found in Appendix Table 1 of ALM. The ALM measures are also employed by Goos and Manning (2007) and Peri and Sparber (2007) among others.

${ }^{24}$ For the 5 percent of microdata observations with the lowest manual task score (which is zero for most of these observations), we use the manual score of the 5 th percentile.
} 
have a cardinal scale, we standardize it with a mean of zero and an employment weighted, cross-CZ standard deviation of unity in 1980. This simple measure appears to capture well the job categories that motivate our conceptual framework. Appendix Table 1 shows that among the 10 most routine task-intensive occupations, 6 are clerical and accounting occupations and several others represent repetitive physical motion activities. Among the 10 least routine task intensive occupations (not tabulated), 4 are service occupations, and the remainder involve driving motor vehicles. ${ }^{25}$

To measure cross-market variation in employment in routine task-intensive occupations, we apply a simple binary approach to distinguish 'routine' and 'non-routine' occupations. We classify as routine occupations those that fall in the top-third of the employment-weighted distribution of the $R T I$ measure in 1980, and we assign to each commuting zone $j$ a routine employment share measure $\left(R S H_{j t}\right)$ equal to the fraction of $\mathrm{CZ}$ employment at the start of a decade that falls in routine taskintensive occupations. The mean of this measure in 1980 is equal to 0.33 by construction, and the population weighted $80 / 20$ percentile difference in routine employment share is 10 percentage points (specifically, $R S H^{P 20}=0.275$ and $\left.R S H^{P 80}=0.373\right) .{ }^{26}$

To provide a point of comparison, we further subdivide the remaining two-thirds of employment into two even halves, using average 1980 occupational wages to allocate occupations to high- and low-wage non-routine clusters. These occupational clusters, described in Appendix Table 1, appear to accord well with the non-routine task categories defined above, i.e., abstract and manual. The high wage non-routine cluster is largely composed of professional specialty and technical occupations, with 54 percent of workers college-educated (relative to 45 percent of workers in routine-intensive occupations) and mean log hourly wages that are 30 log points above the routine occupation mean. The low-wage non-routine group is largely composed of low-education service, labor, and operative occupations, with 27 percent of workers college-educated and mean log hourly wages $24 \log$ points below the routine occupation mean. Notably, average routine task-intensity is closely comparable between high and low-wage non-routine groups, in both cases approximately 1.8 standard deviations below the routine-intensive occupation mean. This reinforces the point that non-routine occupations lie at the poles of the wage distribution whereas routine-intensive occupations are concentrated towards the middle. Routine task-intensity is thus strongly non-monotone in education and wages. ${ }^{27}$

\footnotetext{
${ }^{25}$ Motor vehicle operation closely fits our definition of manual tasks, requiring little formal education but considerable ability to respond flexibly to a changing environment. Such occupations are classified as transportation and material moving rather than service in the Census. These occupations do not, however, possess the strong supplier-demander collocation attribute of service occupations and so are not well suited to our geographic analysis. Of the full set of 31 Census-classified service occupations, 17 fall in the bottom quintile of $R T I$ scores and 23 of fall below the median.

${ }^{26}$ We have experimented with alternative commuting zone routine intensity measures, including counting the share of employment in the top 20 or top 50 percent of routine occupations (rather than the top third) or simply taking the mean routine-intensity score in each commuting zone. All of these measures perform similarly in our analysis.

${ }^{27}$ Trends in aggregate DOT task variables reveal substantial movements in the predicted directions. Standardizing
} 


\section{Predicting the Growth of SERVice EMployment}

A primary implication of our conceptual model is that commuting zones that are initially specialized in routine task activity will experience differential growth of service employment as routine tasks are supplanted by computerization. The scatter plot in the upper panel of Figure 3 provides strong initial support for this prediction by plotting the bivariate relationship between initial commuting zone routine share $\left(R S H_{1980}\right)$ and the change in the share of non-college labor employed in service occupations over the subsequent 25 years. Each plotted point represents one of 722 commuting zones, and the regression line corresponds to the following weighted OLS regression of the change in the service employment share on the initial $R S H$, where weights are equal to commuting zone shares of national population in 1980:

$$
\Delta S V C_{j, 1980-2005}=-0.039+\begin{gathered}
0.323 \times R S H_{j, 1980} \\
(t=18.1)
\end{gathered}+e_{j t} \quad R^{2}=0.31
$$

The explanatory power of this bivariate relationship is substantial. The coefficient of 0.323 on $R S H$ implies that a commuting zone with the mean routine share in 1980 is predicted to increase its share of non-college labor in service employment by 6.9 percentage points between 1980 and 2005, while the expected increase in non-college service employment in the commuting zone at the 80th percentile of $R S H$ is 3.2 percentage greater than in the 20th percentile commuting zone.

To provide insight into the geography of this relationship, the lower panel of Figure 3 plots the bivariate relationship between initial routine share and the growth of service employment for the 40 commuting zones in the sample with populations over 1 million. Each $\mathrm{CZ}$ is identified by the name of its largest city in the figure. The relationship between initial routine share and subsequent growth of service jobs found in this greatly reduced sample is comparable in magnitude to the full sample and is highly significant. This figure also underscores an important characteristic of initially routine occupation-intensive cities: they are not for the most part industrial cities such as Syracuse or Pittsburgh, but rather knowledge-intensive cities like New York, Chicago, and Dallas. Routineintensive occupations, such as clerical work and accounting, were commonplace in these high-skill cities in the 1980s because they serve as supporting occupations to the professions.

Table 2 explores the bivariate relationship between the routine employment share and growth of service employment by decade between 1950 and 2005 using specifications of the following form:

$$
\Delta S V C_{j s \tau}=\alpha_{t}+\beta_{\tau} \times R S H_{j s t}+\gamma_{s}+e_{j s \tau}
$$

each variable with mean zero and cross-commuting zone standard deviation of one in 1980, the abstract task score of the mean commuting zone rises by 1.5 standard deviations over the subsequent 25 years while the routine task score of the mean commuting zone falls by 2.3 standard deviations. The mean manual task score falls by 0.3 standard deviations between 1980 and 1990, plateaus in the subsequent decade, and rises between 2000 and 2005. 
In this equation, $\tau$ represents a decadal change, $t$ denotes the start year of the corresponding decade, and $s$ denotes the state in which the commuting zone is located. ${ }^{28}$ The inclusion of a vector of state dummies, $\gamma$, means that the coefficient of interest, $\beta$, is identified by within-state cross-CZ variation. ${ }^{29}$ A central pattern that emerges from this table is that the strong, positive predictive relationship between the routine employment share and growth of service employment is not detected prior to the decade of the 1980s, and actually has the opposite sign in the 1950 to 1970 period. ${ }^{30}$ Beginning in 1980, this relationship becomes positive and significant, and its magnitude rises in each subsequent time interval.

\subsection{Controlling For Skill Supply, labor market Conditions, And Demographics}

Alongside routine task-intensity, a host of factors may explain geographic variation in the growth of service employment. We explore these factors in Table 3 using an augmented version of equation $(37)$ :

$$
\Delta S V C_{j s \tau}=\alpha+\beta_{1} \times R S H_{j s t} \times I[t \geq 1980]+\beta_{2} \times R S H_{j s t}+\beta_{3} \Delta X_{j s \tau}+\delta_{\tau}+\gamma_{s}+e_{j s \tau} .
$$

This model stacks all decadal changes used in Table 2 over the interval 1950 to 2005, and includes a full set of time period effects, state effects, and measures of contemporaneous changes in a number of relevant human capital, labor market, and demographic variables.

The first column of the table reiterates the finding from estimates of (37) that the strong, positive relationship between routine employment share and growth of service employment found for 1980 through 2005 is not present in prior decades. Column 2 shows that this finding relationship is insensitive to the inclusion of the state dummy variables, which function as state-specific trends in the first-differenced specification. Subsequent columns control for a variety of factors that may contribute to growth of service employment within CZ's.

Column 3 adds two variables intended to capture shifts in the demand and supply of services: the change in the college-educated share of the population and the change in the share of the non-college population that is immigrants. These controls enter with the expected sign: a rise in the highlyeducated population or an increase in immigrant penetration predicts growth in service employment

\footnotetext{
${ }^{28}$ The dependent variable for 1950 to 1970 is divided by two and the one for 2000 to 2005 is multiplied by two to place them on the same decadal time scale.

${ }^{29}$ If a commuting zone contains adjacent counties that cross state boundaries, we implicitly redefine state boundaries so that the commuting zone is located in the state contributing a larger share of its population.

${ }^{30}$ One speculative explanation for the negative relationship between $R S H$ and the growth of service employment is based on the observation that US farm employment contracted rapidly between 1950 and 1970 , falling from 11 to 3 percent of employment. Farm-intensive commuting zones had low levels of the $R S H$ in 1950 . Thus, the movement of labor from farm occupations into services in these CZs may potentially explain the negative relationship between the $R S H$ and growth of service employment in this period.
} 
among non-college workers (Cortes, 2008).

Column 4 adds two variables whose first-differences measure changes in local labor demand conditions: the unemployment rate and the share of employment in manufacturing. Service employment rises significantly when unemployment increases and when manufacturing employment declines.

Column 5 considers two demand shifters: the elderly population share and the female labor force participation rate. Because the elderly have high demand for specific services such as home health assistance, a rising share of senior citizens in the population may contribute to rising service employment, and this pattern is affirmed in column (5). Likewise, many services, such as restaurant meals or housekeeping, serve as substitutes for household production, and so a rise in female labor supply might be expected to raise demand for services (Mazzolari and Ragusa, 2008). Surprisingly, increased female employment is associated with a decline in service employment, though the sign of this relationship is sensitive to inclusion of other controls (see column 6).

Inclusion of the full set of explanatory variables (column 6) substantially raises the explanatory power of the model. Moreover, all control variables are highly significant and have the expected sign. Nevertheless, the robust relationship between initial routine employment share and growth of service employment remains largely intact. Comparing columns (1) and (6), the point estimate on $R S H$ is about 45 percent lower in the most inclusive model, but the precision of the estimate is greater.

Arguably, the empirical approach used by equation (38) is unduly conservative in that it likely 'overcontrols' for contemporaneous factors - including unemployment and contraction of manufacturingthat may stem (in part) from a common underling cause: labor demand shifts against routine-intensive occupations. When specification (38) is re-estimated using as controls start-of-period levels of the six additional explanatory variables rather than contemporaneous changes (panel B), the size and significance of the routine share measure is in most cases slightly larger than above and is also more precisely estimated.

In summary, commuting zones' initial employment concentration in routine-intensive occupations is a robust predictor of their subsequent increases in service employment. Indeed, the routine share measure has greater predictive power for growth of service employment than any other human capital, labor market, or demographic variable that we have identified.

\subsection{Which SERViCe OCCUPATIONS AND Which WORKERs?}

Is the relationship between routine task-intensity and growth of service employment specific to a subset of service occupations or one demographic subgroup? Estimates of equation (38) fit separately for each major service occupation group in Appendix Table 2 find that the aggregate relationship between the routine employment share and subsequent growth of service employment is common 
across a broad set of service occupations including food service, personal appearance, child care, recreation, and building cleaning and gardening. ${ }^{31}$ In fact, point estimates are positive for all nine service occupation categories for 1980-2005 period, and are statistically significant in six. Notably, while health care support occupations are the third largest contributor to service employment growth over 1980 to 2005 (after food service and janitorial services), their growth is not strongly predicted by routine task-intensity. Plausibly, rising demand for health care support services derives from other sources, particularly the aging of the US population.

Complementing the results for occupations, Table 5 estimates equation (38) for four demographic sub-groups of non-college workers. The relationship between the $R S H$ and rising service employment is largest for foreign borns but also positive for US-born workers and for workers of both genders. Females are the only demographic group for whom the relationship between $R S H$ and growth in service employment was already positive prior to 1980. But this relationship accelerated notably after 1980, though the respective coefficient is imprecisely estimated.

\subsection{Changes in Service Employment in matched COMmuting ZOneS}

The results above derive from a comparison of commuting zones that differ initially on numerous observable dimensions in addition to their initial routine employment shares. To attempt to minimize the effect of these potential confounds on inference, we analyze the relationship between routine share and service employment in commuting zones that are matched on their expected routine employment share. Here, we use only the unexpected (residual) variation in routine share to predict service employment growth.

To implement this test, we first estimate a cross-section regression of the 1980 routine share on the full set of covariates used above:

$$
R S H_{j, 1980}=\alpha+\beta \times X_{j, 1980}+\gamma_{s}+e_{j, 1980}
$$

As shown in Appendix Table 3, the explanatory power of this model is substantial, with an R-squared of 0.82 . One might therefore expect that the unexplained variation in $R S H$ would contain mostly noise and so not be especially predictive of subsequent outcomes.

We test this relationship by grouping the 722 commuting zones into evenly sized terciles based on their predicted routine share in 1980, $\widehat{R S H}_{j, 1980}$, from (39). Within each tercile, we regress commuting zone level changes in service employment over 1980 through 2005 on the unexplained component of

\footnotetext{
${ }^{31}$ The 1950 to 1980 comparisons of detailed service occupation employment are somewhat unreliable because the 1950 Census classifies many service workers in broad "not elsewhere classified" categories. This gives rise to large spurious increases in many subcategories of service employment over 1950 to 1980, balanced by an offsetting drop in "miscellaneous service occupations." This consistency issue affects comparisons at this very disaggregated level but does not contaminate the overall measure of service occupation employment.
} 
routine-employment, $\widetilde{R S H}_{j, 1980}=R S H_{j, 1980}-\widehat{R S H}_{j, 1980}$.

Estimates in Table 5 demonstrate a remarkably consistent pattern: the unexplained component of routine employment specialization in 1980 remains strongly predictive of subsequent growth in service employment. Point estimates for $\lambda$ are highly comparable in magnitude across all three terciles, and are significant in one of the three subsamples despite the smaller sample size.

\subsection{Testing alternative Demand-Side explanations}

Growing employment in low-skilled service jobs could alternatively arise from two other demandside forces noted in the Introduction: rising high incomes, which may generate additional demand for outputs of service occupations if they are consumed as luxury goods; and rising market returns to skill, which may spur high skill workers to increase their labor supply and purchase additional household services to compensate for foregone household production, as per Manning (2004) and Mazzolari and Ragusa (2008).

We explore the evidence for these income and substitution effects by augmenting the baseline regression model for 1980 through 2005 with two additional measures. To proxy for wage structure shifts that may generate income effects, we use changes in the 90th percentile of the log weekly wage distribution among full-time, full-year workers in each commuting zone. ${ }^{32}$ As a measure of the labor supply of high-skilled workers, we use changes in mean annual hours worked among college-graduates in each commuting zone. These outcomes are, as expected, strongly predicted by the initial routine share variable, $R S_{j, 1980}$. High wages and high-skilled hours rose by significantly more over 1980 through 2005 in commuting zones that were initially specialized in routine-intensive employment. ${ }^{33}$

Despite their substantial correlations with $R S H$, estimates in Table 6 indicate that these proxies for income and substitution effects are not predictive of growth in service employment. Growth in the 90th percentile weekly wage is only weakly correlated with rising service employment, and this relationship turns negative when the $R S H$ variable is added. Annual hours worked by college graduates is negatively related to service employment growth, and this is true whether we measure college labor labor overall or separately by gender. Notably, the $R S H$ variable remains in all cases highly predictive of rising service employment, and is essentially unaffected by inclusion of these controls.

In summary, the results in Tables 3 through 6 provide robust support for a key prediction of the

\footnotetext{
${ }^{32}$ This distributional statistic is arguably the best proxy of the market price of 'high' skills available from the Census data since it captures the wage commanded by workers with strong labor force attachment. Other wage measures considered yield similar results but have lower explanatory power.

${ }^{33}$ Regression estimates imply that the $\mathrm{CZ}$ at the 80 th percentile of $R S H$ in 1980 experienced 8 log points greater growth in the $P 90$ and 11 additional hours greater increase in annual hours of labor supply per college graduate than the 20th percentile commuting zone per decade over the 1980 - 2005 period. A full table of results is available from the authors.
} 
conceptual model: geographic areas that were specialized in routine-intensive occupations prior to the era of rapid computerization experienced significantly greater growth of service employment in the ensuing decades. This predictive relationship is pervasive across categories of service work, and affects employment trends among different groups of non-college workers, i.e., male and female, foreign and US-born. The link between the routine employment share and rising service employment does not take hold until the 1980s, and it accelerates in the two subsequent decades. Most notably, this simple measure of occupational structure appears to capture a significant dimension of local economic activity that is not well measured by a host of other labor supply, labor demand, and demographic proxies, including education, immigration, unemployment, female labor force participation, and population aging, as well as proxies for other demand-side forces. Subsequent sections explore further predictions of the model, using the $R S H$ measure as a key predictive variable.

\section{TASk specialization, COMputer adoption, AND WAGE inequality}

Our conceptual model makes four further predictions about the relationship between initial specialization in routine occupations and subsequent commuting zone level outcomes, each of which we briefly explore below. First, displacement of routine labor input should lead to shifts in job specialization, as workers - particularly the less-educated - move out of routine-intensive occupations. Second, computer adoption should be more extensive in CZ's undergoing these changes, since higher routine task-intensity implies greater demand for computer capital to substitute for workers performing routine tasks. Third, changing task prices should spur a rise in earnings inequality - particularly in the upperhalf of the distribution - as the abstract task price rises relative to the routine task price. Finally, wages in service occupations may rise relative to other activities performed by less skilled workers in the same commuting zones if goods and services are complements in consumption. As noted in section (2), the 'price' implications of our model are less theoretically robust than the 'quantity' implications since they hinge on imperfect arbitrage of wage rates across commuting zones.

\subsection{TASK SPECIALIZATION}

In our conceptual model, the differential rise in service employment evident in routine task-intensive regions is one important manifestation of a broader phenomenon of shifting task specialization away from routine-intensive labor and towards manual and abstract tasks. We take a broader look at changes in occupational specialization by estimating a variation of equation (38) in which the dependent variable is the change in routine and non-routine employment shares within a commuting zone, overall and within broad education categories.

The top panel of Table 7 shows that during 1980 through 2005, commuting zones with higher 
initial routine employment shares saw larger subsequent declines in routine-intensive employment. The column (1) estimate indicates that the 80th percentile commuting zone lost approximately 2.4 percentage points more routine employment per decade than did the 20 th percentile CZ. ${ }^{34}$ Columns (2) and (3) of the table estimate this relationship separately for college and non-college workers. Both estimates are highly significant, but interestingly the decline in routine employment is greater for non-college workers (high school or lower education) than for college workers (at least one year of college). Thus, consonant with the model, the recent movement out of routine-intensive occupations is concentrated among less educated workers. ${ }^{35}$

If the movement out of routine-intensive work reflects a change in specialization, in what activities do workers specialize instead? Using our prior division of non-routine occupations into highand low-wage groups (Appendix Table 1), panels $\mathrm{B}$ and $\mathrm{C}$ of Table 7 show that relative declines in routine occupations within CZs are primarily offset by relative employment gains in low-skill nonroutine occupations - jobs that are on average significantly less skill-intensive and lower-paying than the routine occupations that are displaced. The degree of downward movement differs substantially, however, between college and non-college workers. Among the college-educated, movement out of routine-intensive occupations is approximately equally absorbed by movements into high- and lowwage non-routine occupations. Among non-college workers, by contrast, occupational reallocation is entirely accounted for by employment gains in low-wage, non-routine jobs. ${ }^{36}$

In net, declines in routine-intensive work lead to employment polarization, as suggested by the conceptual model, with labor reallocation away from 'middle-skilled' jobs and towards occupations at either end of the skill and wage distribution. Downward movements are much more evident among non-college workers, however, likely because they have a comparative advantage in manual relative to abstract tasks, while the reverse is true for college-educated workers.

\subsection{Computer Adoption}

A foundational but as yet untested assumption of our analytic framework is that the decline in routine labor input within commuting zones reflects substitution of information technology for workers engaged in routine tasks. We test this supposition using a measure of geographic computer penetration

\footnotetext{
${ }^{34}$ Estimates for the full 1950 - 2005 period find a negative significant relationship between start of period $R S H$ and movements out of routine-intensive occupations even prior to the 1980s. But the magnitude of this relationship increases by more than 50 percent after 1980 .

${ }^{35}$ Concretely, it appears likely that less educated workers in routine-intensive occupations perform a disproportionate share of routine tasks and thus are differentially subject to displacement. Michaels (2007) finds that clerical occupations demanded highly educated labor at the start of the twentieth century. But by the 1950s, these were no longer elite occupations.

${ }^{36}$ Autor and Dorn (2009) further consider how occupational movements between routine and non-routine occupations differ by age as well as education.
} 
developed by Doms and Lewis (2006). Based on private sector surveys on computer inventories, these data measure the number of personal computers per employee at the firm level — which is a relevant, though incomplete, measure of computer adoption. Doms and Lewis aggregate this variable to the level of local labor markets and purge it of industry by establishment-size effects using a linear regression model. We use the Doms and Lewis 'adjusted computers-per-worker' measure for the years 1990 and 2002, which is matched to commuting zones. ${ }^{37}$ Following the approach of Doms, Dunne and Troske (1997), we treat the 1990 level of this variable as the 'change' from 1980 to 1990, thus assuming that the level was close to zero in all areas in 1980. We measure the change in this variable over the subsequent decade using $5 / 6$ of the 1990 to 2002 first-difference. ${ }^{38}$

We estimate models predicting computer adoption (PCs per worker) across commuting zones of the form:

$$
\Delta C_{j s \tau}=\alpha+\beta_{1 \tau} \times R S H_{j s t}+\beta_{2 \tau} \Delta X_{j s \tau}+\gamma_{s}+e_{j s \tau},
$$

where the dependent variable is the Doms-Lewis measure of computer adoption over time interval $\tau$ in commuting zone $j$ in state $s$, and the other variables follow our notation above. The first two columns of Table 8 present separate, by-decade OLS regressions of commuting zone computer adoption during the 1980s and 1990s on the $R S$ measure, state dummies and a constant. The $R S$ has substantial predictive power for computer adoption in both decades, with t-ratios well over 9 . The implied difference in computer adoption between the 80th and 20th percentile commuting zones is larger than one full standard deviation of the computer adoption measure in each decade.

Subsequent columns of Table 8 probe the robustness of this relationship by regressing the stacked decadal changes in computer adoption on initial $R S H$ and the full set of contemporaneous labor force and demographic change variables used earlier. Notably, all of these covariates are significant predictors of computer adoption in this time period. The $R S H$ measure proves highly robust to their inclusion; with these variables added, its magnitude drops by less than a third and the t-ratio remains large. Hence, commuting zones that were initially specialized in routine task-intensive occupations adopted computer technology at a differentially rapid rate over the subsequent two decades.

\subsection{WAGE INEQUALITY}

We finally explore the relationship between task specialization and wage inequality. The analysis first examines the relationship between a commuting zone's routine share and the evolution of its

\footnotetext{
${ }^{37}$ We thank Mark Doms and Ethan Lewis for providing this data. Approximately 50 of the 722 commuting zones do not have corresponding computer adoption data and so are dropped from the analysis.

${ }^{38}$ The level of the PC-per-worker measure is not readily interpretable because it is a regression residual, as explained above. The cross commuting zone standard deviation of this change in this variable is 0.048 for $1980-1990$ and 0.053 for 1990-2000.
} 
aggregate wage inequality — in particular, earnings polarization — as measured by the 90/50 and 50/10 log wage ratios. We next turn to microdata to provide a tightly controlled analysis of changes in wage structure between occupations within commuting zones, holding constant all observable determinants of earnings.

\subsubsection{Aggregate wage structure}

We estimate stacked first-difference regressions for changes in wage inequality within commuting zones over 1980-2005, as measured by the 90/10, 90/50 or 50/10 log weekly wage ratio for full-time, full-year workers. Following the format of earlier equations, all models include the start-of-period $R S H$, and a full set of state and time dummies, with alternate specifications containing the full set of labor market and demographic controls used above.

The estimates in Table 9 reveal a striking pattern: commuting zones with a greater routine employment share in 1980 saw a large, differential rise in earnings inequality. In particular, the point estimate in column(2) implies that, conditional on the full set of control variables used earlier, overall (90/10) inequality is predicted to have risen by 3.4 additional log points per decade in the $\mathrm{CZ}$ at the 80th percentile of $R S H$ relative to the $\mathrm{CZ}$ at the 20 th percentile over this time interval. ${ }^{39}$ Subsequent columns of the table show that this aggregate 90/10 relationship is driven by movements in the upper-tail of the wage distribution: $R S H$ is robustly predictive of a rise in 90/50 inequality. By contrast, its relationship to lower tail inequality is negligible when other factors are controlled. These results indicate that the wage polarization seen in aggregate wage data for this time period (Figure 1) is evident at the commuting zone level and is concentrated in commuting zones experiencing rapid displacement of routine work.

\subsubsection{EvidenCE FROM MiCRODATA}

Do these patterns of aggregate wage structure change affecting commuting zones specialized in routine employment primarily reflect compositional shifts in worker and occupational characteristicsor, rather, changes in the wages paid to given worker characteristics within a geographic area? To answer this question, we pool microdata on real log hourly wages from the 1980 Census and the 2005 American Community Survey to estimate a set of OLS log wage equations of the following form:

$$
\begin{aligned}
\ln w_{i j k t}= & \alpha_{k}+\beta_{1 k}\left\{R S H_{j, 1980} \times I[t=2005]\right\} \\
& +X_{i j k t}^{\prime} \beta_{2 k t}+\delta_{j k}+\gamma_{j k}+e_{i j k t},
\end{aligned}
$$

\footnotetext{
${ }^{39}$ Notably, estimates for the full 1950-2005 period (available from the authors) show that these relationships are either substantially smaller or of opposite sign in the prior three decades. To benchmark magnitudes, note that the weighted mean rise in 90/10 inequality in CZ's for 1980-2005 was 7.3 log points per decade.
} 
where $i$ denotes workers, $j$ denotes commuting zones, $k$ denotes occupation, and $t$ denotes times (1980, 2005). These models include time dummies, commuting-zone dummies, a full set of personlevel covariates interacted with time dummies, and an interaction between the start-of-period routine employment share and the 2005 dummy. We perform estimates separately for each of the major occupation categories in Table 1 (except for farm occupations). Standard errors are clustered at the commuting zone by year level since to account for the fact that the main predictive variable, $R S H$, does not vary within commuting zones. ${ }^{40}$

Estimates in the first two columns of Table 10 show that commuting zones specialized in routine employment in 1980 saw large real wage increases among workers in the two occupation groups with highest education levels between 1980 and 2005. A 10 percentage point higher routine share in 1980 predicts $6.2 \mathrm{log}$ points greater wage growth in managerial and professional occupations and $9.7 \log$ points greater wage growth in technical, sales and administrative occupations (both for males) over these two decades. Estimates for females are somewhat larger in professional occupations and smaller in administrative occupations.

The next two columns estimate analogous wage models for workers in production and operative occupations - many of them corresponding to middle-skill ('routine') occupations in our conceptual framework. Opposite to the pattern for highly-skilled occupations, a higher routine share of employment in 1980 predicts significant real wage declines in these occupations. ${ }^{41}$

The fifth column presents wage estimates for workers in service occupations. Distinct from other low-education occupations (i.e., production workers and operatives), the relationship between initial routine task share and service wages is small in magnitude and not significant. When wages in service occupations are directly compared to those in productive and operative positions in the final column, relative wage growth in service occupations is found to be greater in routine-occupation intensive commuting zones.

The second row of each panel of Table 10 re-estimates these models, augmented with a full set of person-level demographic controls, including nine dummies for years of education, a quartic in potential experience, and dummies for married, non-white and foreign-born. These covariates are further interacted with time dummies to allow their slopes to differ by period. The pattern of results is only modestly affected by the inclusion of these additional variables. Estimates for high-skilled occupations are essentially unaffected. Estimates for production and operative occupations become less negative

\footnotetext{
${ }^{40}$ We also experimented with clustering estimates by state and year. Because this produced smaller standard errors, we conservatively report the CZ-by-year standard errors in the table.

${ }^{41}$ While the precision of the point estimate for wages of females in production occupations is low, the table also makes evident that there are only 10 percent as many females as males in production occupations, whereas there are 40 percent as many females as males in operative occupations.
} 
or even positive, indicating that part of the negative wage relationship is due to adverse changes in skill composition in these occupations in initially routine-intensive commuting zones. Finally, the estimates for service occupation wages become positive for both males and females, suggesting that compositional shifts may mask rising real wages in these occupations. ${ }^{42}$

Reinforcing the earlier results for 90/50 and 50/10 wage inequality, these microdata estimates confirm that commuting zones that were previously specialized in routine jobs saw a distinct pattern of polarizing wage growth among occupations over the subsequent 25 years, with strongly rising wages in high-skill occupations, declining wages in moderately-skilled production and operative occupations, and stable wages in low-skill service occupations. The data clearly support the view that displacement of routine tasks within commuting zones is accompanied by relative growth in both service employment and service wages. What makes this finding particularly compelling is that service occupations are the only low-skill job category that appears to benefit from this process.

\section{Conclusions}

While the past 25 years have seen declining or stagnating real (and relative) earnings and employment of less educated workers, employment in low-skill service occupations presents a striking exception. Between 1980 and 2005, the share of hours worked in service occupations among those with high school or lower education rose by more than 50 percent. Simultaneously, real hourly wages in service occupations increased by 17 log points, considerably exceeding wage growth in other low-skill occupations. In fact, the upward twisting of the lower-tail of the U.S. earnings and job distributions commencing in the 1990s is substantially accounted for by rising employment and wages in service occupations.

We offer a hypothesis for the rising demand for service work based on changes in task specialization induced in part by technical change. Our conceptual framework builds from the observation that the primary job tasks of service occupations are difficult to either automate or outsource since these tasks require interpersonal and environmental adaptability as well as direct physical proximity. Our conceptual model shows that if the demand for the outputs of service occupations does not admit close substitutes, the substitution of information technology for routine tasks used in goods production may, in the long run, lead to rising wages and employment in service occupations.

Motivated by the observation that workers in service occupations must collocate with demanders of their services, we study the determinants of employment and wages in services during 1950 through 2005 in 722 consistently defined commuting zones covering all of U.S. mainland employment. The

\footnotetext{
${ }^{42}$ These results underscore that rising relative wages in service relative to other low-education occupations in Table 10 are unlikely to be driven by unobserved selection of relatively high-skilled workers into service jobs.
} 
analysis contrasts the period 1980 to 2005 during which a rapid adoption of information technology took place with a previous period from 1950 to 1980. We use an empirical approach built on the theoretical model, which predicts that, if commuting zones differ initially in the share of employment in routine-intensive occupations, markets with higher routine shares will see larger increases in service occupation employment and greater polarization of earnings between high and middle-skill workers as time advances. If goods and services are sufficiently complementary, the model further implies that wages in service occupations will rise along with service employment.

We explore these predictions using a simple measure of initial specialization in routine-taskintensive employment based on the occupational structure of commuting zones at the start of the sample period. This measure proves strikingly predictive of the changes in task and wage structure implied by the model: reallocation of labor activity away from routine tasks; employment growth in low-skilled service occupations; differential adoption of information technology; and polarization of earnings growth. Thus, the changes in task structure that we document accompany growth in wages at the tails of the distribution but not elsewhere.

These findings reveal a process of employment and wage polarization within regional labor markets that parallels the polarization of employment seen at the aggregate level in the U.S., the U.K. and West Germany. Our results suggest an important role for changes in labor specialization - potentially spurred by displacement of routine task activities - as a driver of rising employment and wages in service occupations, and of polarization of employment and wage growth more generally.

\section{REFERENCES}

Acemoglu, Daron. 1999. "Changes in Unemployment and Wage Inequality: An Alternative Theory and Some Evidence." American Economic Review, 89 (December), 1259-1278.

Autor, David H. and David Dorn. 2009. "This Job is "Getting Old": Measuring Changes in Job Opportunities using Occupational Age Structure." American Economic Review Papers and Proceedings, 99(2), 45-51.

Autor, David H., Lawrence F. Katz, and Melissa S. Kearney. 2006. "The Polarization of the U.S. Labor Market." American Economic Review, 96:2 (May), 189-194.

Autor, David H., Lawrence F. Katz, and Melissa S. Kearney. 2008. “Trends in U.S. Wage Inequality: Revising the Revisionists." Review of Economics and Statistics. 90(2), May, 300-323.

Autor, David H., Frank Levy, and Richard J. Murnane. 2003. "The Skill Content of Recent Technological Change: An Empirical Investigation." Quarterly Journal of Economics, 118(3), November, 1279-1333. 
Baumol, William J. 1967. "Macroeconomics of Unbalanced Growth: Anatomy of an Urban Crisis." American Economic Review, 57(3), June, 415-426.

Beaudry, Paul and David A. Green. 2003. "Wages and Employment in the United States and Germany: What Explains the Differences?" American Economic Review, 93(3), 573-602.

Beaudry, Paul, Mark Doms, and Ethan Lewis. 2006. "Endogenous Skill Bias in Technology Adoption. City-Level Evidence from the IT Revolution." NBER Working Paper 12521, September.

Blanchard, Olivier Jean and Lawrence F. Katz. 1992. "Regional Evolutions." Brookings Papers on Economic Activity, 1992(1), 1-75.

Card, David and John E. DiNardo. 2002. "Skill-Biased Technological Change and Rising Wage Inequality: Some Problems and Puzzles." Journal of Labor Economics, 20, October, 733-83.

Clark, Colin. 1957. The Conditions of Economic Progress. London: Macmillan.

Cortes, Patricia. 2008. "The Effect of Low-Skilled Immigration on U.S. Prices: Evidence from CPI Data," Journal of Political Economy, 116(3), 381-422.

DiNardo, John E., Nicole M. Fortin, and Thomas Lemieux. 1996. "Labor Market Institutions and the Distribution of Wages, 1973-1992: A Semiparametric Approach," Econometrica, 64(5), 1001-1044.

Doms, Mark E., Timothy Dunne, and Kenneth R. Troske. 1997. "Workers, Wages, and Technology." Quarterly Journal of Economics, 112(1), 253-290.

Doms, Mark E. and Ethan G. Lewis. 2006. "Labor Supply and Personal Computer Adoption." Federal Reserve Bank of Philadelphia Working Paper No. 06-10, June.

Dorn, David. 2009. "Essays on Inequality, Spatial Interaction, and the Demand for Skills." Dissertation University of St. Gallen no. 3613, September 2009.

Dustmann, Christian, Johannes Ludsteck and Uta Schönberg. 2007. "Revisiting the German Wage Structure." Mimeograph, University of Rochester, February.

Glaeser, Edward L. and Joseph Gyourko. 2005. "Urban Decline and Durable Housing." Journal of Political Economy, 113(2), 345-375.

Goos, Maarten and Alan Manning. 2003. "Lousy and Lovely Jobs: The Rising Polarisation of Work in Britain." CEPR Working Paper No. 0604, December.

Goos, Maarten and Alan Manning. 2007. "Lousy and Lovely Jobs: The Rising Polarization of Work in Britain." Review of Economics and Statistics 89 (February), 118-133.

Goos, Maarten, Alan Manning, and Anna Salomons. 2009. "Job Polarization in Europe." American Economic Review Papers and Proceedings, 99(2), May.

Harrison, Bennett and Barry Bluestone. 1988. The Great U-turn : Corporate Restructuring and the Polarizing of America. New York: Basic Books.

Hecker, Daniel E. 2005. "Occupational Employment Projections to 2014." Monthly Labor Review, 
128(11): 70-101.

Jaeger. David A., Susanna Loeb, Sarah E. Turner and John Bound. 1998. "Coding Geographic Areas across Census Years: Creating Consistent Definitions of Metropolitan Areas." NBER Working Paper W6772, October.

Juhn, Chinhui. 1994. "Wage Inequality and Industrial Change: Evidence from Five Decades." NBER Working Paper No. 4684, March.

Juhn, Chinhui. 1999. "Wage Inequality and Demand for Skill: Evidence from Five Decades." Industrial and Labor Relations Review, 52(3), April, 424-443.

Katz, Lawrence F. and David H. Autor. 1999. "Changes in the Wage Structure and Earnings Inequality." In O. Ashenfelter and D. Card, eds. Handbook of Labor Economics, volume 3, North Holland.

Lemieux, Thomas. 2006. "Increased Residual Wage Inequality: Composition Effects, Noisy Data, or Rising Demand for Skill." American Economic Review, 96, June, 461-498.

Lemieux, Thomas. 2008. "The Changing Nature of Wage Inequality." Journal of Population Economics, 21(1), January, 21-48.

Leonardi, Marco. 2008. "Product Demand Shifts and Wage Inequality." University of Milan Working Paper, October.

Manning, Alan. 2004. "We Can Work it Out: the Impact of Technological Change on the Demand for Low-Skill Workers." Scottish Journal of Political Economy, 51(5), November, 581-608.

Mazzolari, Francesca and Giuseppe Ragusa. 2008. "Spillovers from High-Skill Consumption to Low-Skill Labor Markets." Mimeograph, University of California at Irvine, May.

Meyer, Peter B. and Anastasiya M. Osborne. 2005. "Proposed Category System for 1960-2000 Census Occupations. Bureau of Labor Statistics Working Paper 383, September.

Michaels, Guy. 2007. "The Division of Labor, Coordination, and the Demand for Information Processing." CEPR Working Paper DP 6358, June.

Ngai, L. Rachel and Christopher Pissarides. 2007. "Structural Change in a Multisector Model of Growth." American Economic Review, 97(1), March, 429-443.

Oliner, Stephen D. and Daniel E. Sichel. 2000. "The Resurgence of Growth in the Late 1990s: Is Information Technology the Story?" Journal of Economic Perspectives, 14(4), Fall, 3-22.

Peri, Giovanni and Chad Sparber. 2007. "Task Specialization, Comparative Advantages and the Effects of Immigration on Wages." Mimeograph, University of California at Davis, July.

Pinker, Steven. 2007. The Stuff of Thought: Language as a Window into Human Nature. New York: Viking Adult (Penguin).

Ruggles, Steven, Matthew Sobek, Trent Alexander, Catherine A. Fitch, Ronald Goeken, Patricia 
Kelly Hall, Miriam King, and Chad Ronnander. 2004. Integrated Public Use Microdata Series: Version 3.0 [Machine-readable database]. Minneapolis, MN: Minnesota Population Center [producer and distributor].

Simon, Curtis J. 2004. "Industrial Reallocation across U.S. Cities, 1977-1997." Journal of Urban Economics, 56, 199-143.

Smith, Christopher L. 2008. "Implications of Adult Labor Market Polarization for Youth Employment Opportunities." MIT working paper, July 2008.

Spitz-Oener, Alexandra. 2006. "Technical Change, Job Tasks and Rising Educational Demands: Looking Outside the Wage Structure." Journal of Labor Economics 24 (April), 235-270.

Tolbert, Charles M. and Molly Sizer Killian. 1987. "Labor Market Areas for the United States." Staff Report No. AGES870721. Washington, DC: Economic Research Service, U.S. Department of Agriculture.

Tolbert, Charles M. and Molly Sizer. 1996. "U.S. Commuting Zones and Labor Market Areas. A 1990 Update." Economic Research Service Staff Paper No. 9614.

Topel, Robert H. 1986. "Local Labor Markets." Journal of Political Economy, 94(3), 111-143.

U. S. Department of Labor, Employment and Training Administration. 1977. Dictionary of Occupational Titles: Fourth Edition (Washington, DC: US Government Printing Office).

Weiss, Matthias. 2008. "Skill-biased Technical Change: Is There Hope for the Unskilled?" Economics Letters, 100(3), September, 439-441.

\section{THEORY APPENDIX}

Here we derive the solution to the model for a case where $L_{r}$ and $K$ are complements $(\mu<1)$. Note that we have $K(t) \rightarrow \infty$, so

$$
\lim _{t \rightarrow \infty}\left[(1-\lambda)\left(\alpha_{r} L_{r}(t)\right)^{\mu}+\lambda\left(\alpha_{k} K(t)\right)^{\mu}\right]^{\beta / \mu}=(1-\lambda)^{\beta / \mu}\left(\alpha_{r} L_{r}^{*}\right)^{\beta} .
$$

Consequently,

$$
\begin{aligned}
\lim _{t \rightarrow \infty} F\left(1, g\left(L_{m}(t)\right), t\right) & =\lim _{t \rightarrow \infty}\left[(1-\lambda)\left(\alpha_{r} L_{r}(t)\right)^{\mu}+\lambda\left(\alpha_{k} K(t)\right)^{\mu}\right]^{\beta / \mu}-\theta e^{-\delta t} K(t) \\
& \leq \lim _{t \rightarrow \infty}\left[(1-\lambda)\left(\alpha_{r} L_{r}(t)\right)^{\mu}+\lambda\left(\alpha_{k} K(t)\right)^{\mu}\right]^{\beta / \mu} \\
& =(1-\lambda)^{\beta / \mu}\left(\alpha_{r} g\left(L_{m}^{*}\right)\right)^{\beta}
\end{aligned}
$$

Moreover, since $K(t)$ solves Eq. (17), it does better than an arbitrary choice for the capital 
function. In particular, it does better than $\tilde{K}(t)=t$. Then, we have

$$
\begin{aligned}
\lim _{t \rightarrow \infty} F\left(1, g\left(L_{m}(t)\right), t\right) & \geq \lim _{t \rightarrow \infty}\left[(1-\lambda)\left(\alpha_{r} L_{r}(t)\right)^{\mu}+\lambda\left(\alpha_{k} \tilde{K}(t)\right)^{\mu}\right]^{\beta / \mu}-\theta e^{-\delta t} \tilde{K}(t) \\
& =\lim _{t \rightarrow \infty}\left[(1-\lambda)\left(\alpha_{r} L_{r}(t)\right)^{\mu}+\lambda\left(\alpha_{k} \tilde{K}(t)\right)^{\mu}\right]^{\beta / \mu} \\
& =(1-\lambda)^{\beta / \mu}\left(\alpha_{r} g\left(L_{m}^{*}\right)\right)^{\beta} .
\end{aligned}
$$

Combining Eqs. (43) and (44), we have

$$
\lim _{t \rightarrow \infty} F\left(1, g\left(L_{m}(t)\right), t\right)=(1-\lambda)^{\beta / \mu}\left(\alpha_{r} g\left(L_{m}^{*}\right)\right)^{\beta} .
$$

In words, since $L_{r}$ and $K$ are gross complements and $K$ grows, in the limit $L_{r}(t)=g\left(L_{m}(t)\right)$ becomes the bottleneck and determines the production.

Next consider

$$
\frac{d F\left(1, g\left(L_{m}(t)\right), t\right)}{d L_{r}(t)}=\beta(1-\lambda) \alpha_{r}^{\mu} L_{r}(t)^{\mu-1}\left[(1-\lambda)\left(\alpha_{r} L_{r}(t)\right)^{\mu}+\lambda\left(\alpha_{k} K(t)\right)^{\mu}\right]^{(\beta-\mu) / \mu} .
$$

Since $K(t) \rightarrow \infty$, taking the limit of this expression yields

$$
\lim _{t \rightarrow \infty} \frac{d F\left(1, g\left(L_{m}(t)\right), t\right)}{d L_{r}(t)}=\beta(1-\lambda)^{\beta / \mu} \alpha_{r}^{\beta} g\left(L_{m}^{*}\right)^{\beta-1} .
$$

Taking the limit of Eq. (24) and plugging in Eqs. (45) and (47), we have

$$
\left[(1-\lambda)^{\beta / \mu}\left(\alpha_{r} g\left(L_{m}^{*}\right)\right)^{\beta}\right]^{1 / \sigma_{c}}=-L_{m}^{* 1 / \sigma_{c}} \log \left(1-L_{m}^{*}\right) \beta(1-\lambda)^{\beta / \mu} \alpha_{r}^{\beta} g\left(L_{m}^{*}\right)^{\beta-1} .
$$

The equilibrium level of $L_{m}^{*}$ in the limit is the solution to the previous equation, which will be in the interval $(0,1)$.

Moreover, in this case we have

$$
p_{s} \rightarrow p_{s}^{*}, w_{m} \rightarrow w_{m}^{*}, w_{r} \rightarrow w_{r}^{*}, w_{a} \rightarrow w_{a}^{*}, \eta \rightarrow \eta^{*},
$$

i.e. all variables converge to a finite constant. Intuitively, in this case machines and routine labor are gross complements so technological progress is not sufficient to increase output beyond a finite limit (since routine labor becomes the bottleneck). Consequently, the price of services and hence the wage for the manual labor also remain constant. The wage for routine labor remains constant since the routine labor is the bottleneck so there is still value to routine tasks. The abstract wage is also constant since the abstract workers receive a constant share of output, which is constant.

In this case, $w_{a}(t) / w_{m}(t)$ ratio also goes to a constant $w_{a}^{*} / w_{m}^{*}$ regardless of $\sigma_{c}$, in contrast with the conjecture. We summarize our results in the following proposition. 
Proposition 3 When $\mu<0, \lim _{t \rightarrow \infty} L_{m}(t)=L_{m}^{*}$ where $L_{m}^{*} \in(0,1)$ is a solution to Eq. (48). In the limit, unskilled labor works in both manual and routine tasks and the wages limit to finite levels

$$
\begin{gathered}
w_{m} \rightarrow w_{m}^{*}, w_{r} \rightarrow w_{r}^{*}, w_{a} \rightarrow w_{a}^{*} . \\
7 \text { DATA APPENDIX }
\end{gathered}
$$

\subsection{Measuring Labor Supply and EARnings}

Our sample of workers consists of individuals who were between age 16 and 64 and who were working in the year preceding the survey. Residents of institutional group quarters such as prisons and psychiatric institutions are dropped along with unpaid family workers. Labor supply is measured by the product of weeks worked times usual number of hours per week. For individuals with missing hours or weeks, labor supply weights are imputed using the mean of workers in the same educationoccupation cell, or, if the education-occupation cell is empty, the mean of workers in the same education group. All calculations are weighted by the Census sampling weight multiplied with the labor supply weight and the weight derived from the geographic matching process.

The computation of wages excludes self-employed workers and individuals with missing wages, weeks or hours. Hourly wages are computed as yearly wage and salary income divided by the product of weeks worked and usual weekly hours. Topcoded yearly wages are multiplied by a factor of 1.5 and hourly wages are set not to exceed this value divided by 50 weeks times 35 hours. Hourly wages below the first percentile of the national hourly wage distribution are set to the value of the first percentile. The computation of full-time full-year weekly wages is based on workers who worked for at least 40 weeks and at least 35 hours per week. Wages are inflated to the year 2004 using the Personal Consumption Expenditure Index in order to be comparable to those of the 2005 ACS.

\subsection{Matching Census geography to commuting zones (CZs)}

We matched the geographic information that is available in the Census Public Use samples to the CZ geography. The most disaggregated geographic unit reported in the Census samples is the Public Use Micro Area (PUMA or, prior to 1990, the similarly defined county groups or state economic areas. A PUMA is a subarea of a state that comprises a population of 100,000 to 200,000 persons but has otherwise no clearly inherent economic interpretation. The 2000 Census splits the U.S. into more than 2,000 PUMAs.

The Census Bureau reports how the population of a PUMA is distributed over counties. If a PUMA overlaps with several counties, our procedure is to match PUMAs to counties assuming that all residents of a PUMA have the same probability of living in a given county. The aggregation of 
counties to $\mathrm{CZs}$ then allows computing probabilities that a resident of a given PUMA falls into a specific CZ. Many PUMAs (81population characteristics of residents of each CZ consistently in each year of our data.

\subsection{BUilding COnsistent occupations}

The Census classification of occupations changed over time, particularly between 1970 and 1980 and between 1990 and 2000. We use a slightly modified version of the crosswalk developed by Meyer and Osborne (2005) to create time-consistent occupation categories. Our changes create a balanced panel of 330 occupations for the years 1980 to 2005 that allows to follow a consistently defined set of occupations over time. The occupation categories of the 1950 to 1970 Census are also matched to this occupation system but not all 330 occupations are observed in every year.

The designation of occupations as "service occupations" is based on the occupational classification of the 2000 Census. We subdivide service occupations into nine groups: food preparation and service workers; building and grounds cleaning workers and gardeners; health service support workers (such as health and nursing aides, but excluding practical or registered nurses); protective service workers; housekeeping, cleaning and laundry workers; personal appearance workers (such as hairdressers and beauticians); child care workers; recreation and hospitality workers (such as guides, baggage porters, or ushers); and other personal service workers. Protective service occupations are further subdivided into policemen and fire fighters, and guards. Because police officers and firefighters have much higher educational attainment and wage levels than all other service workers, we exclude them from our primary definition of service occupations (though our results are not sensitive to their inclusion). Details of the construction of the occupational classification are given in Dorn (2009). 
Figure 1a

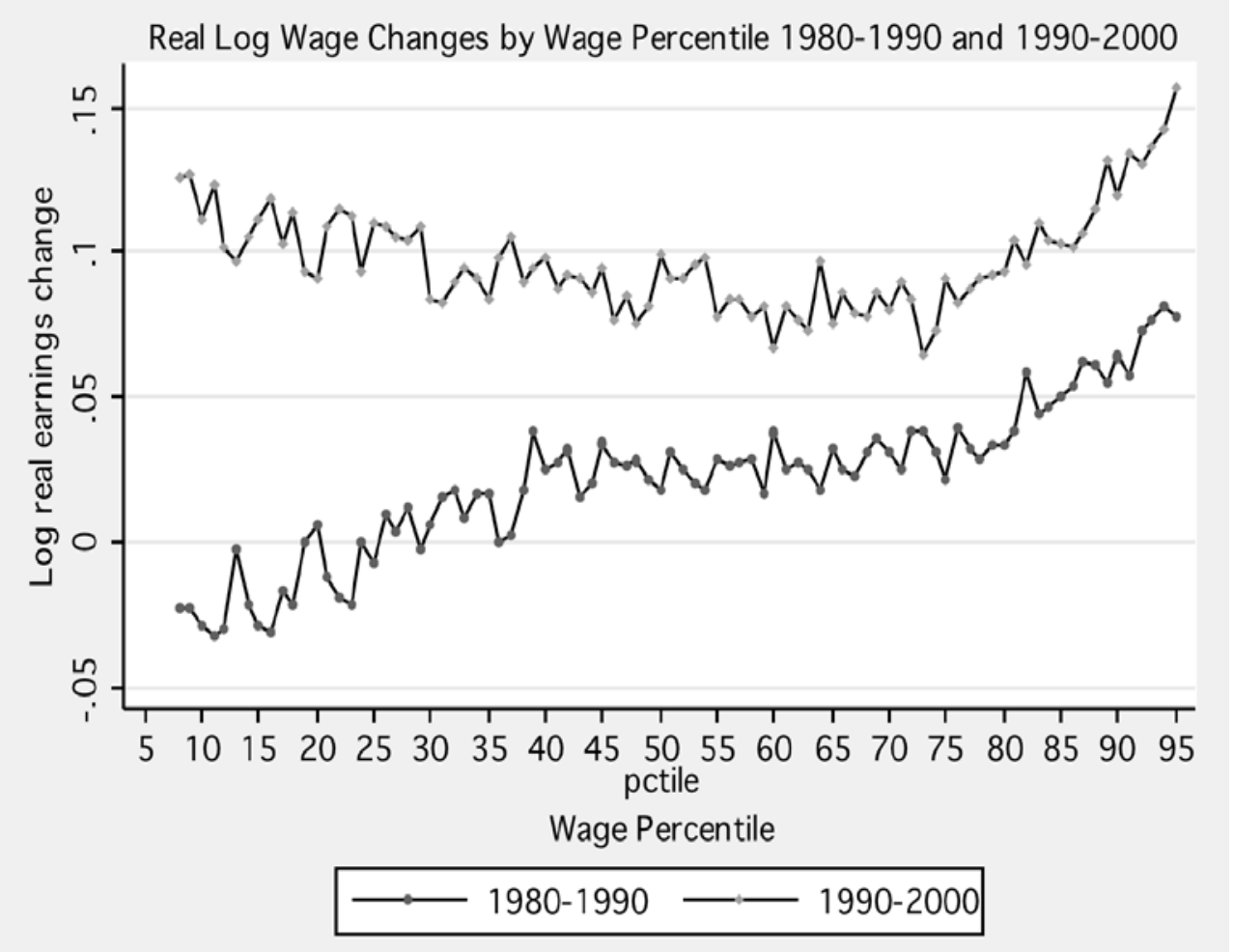

Figure 1b

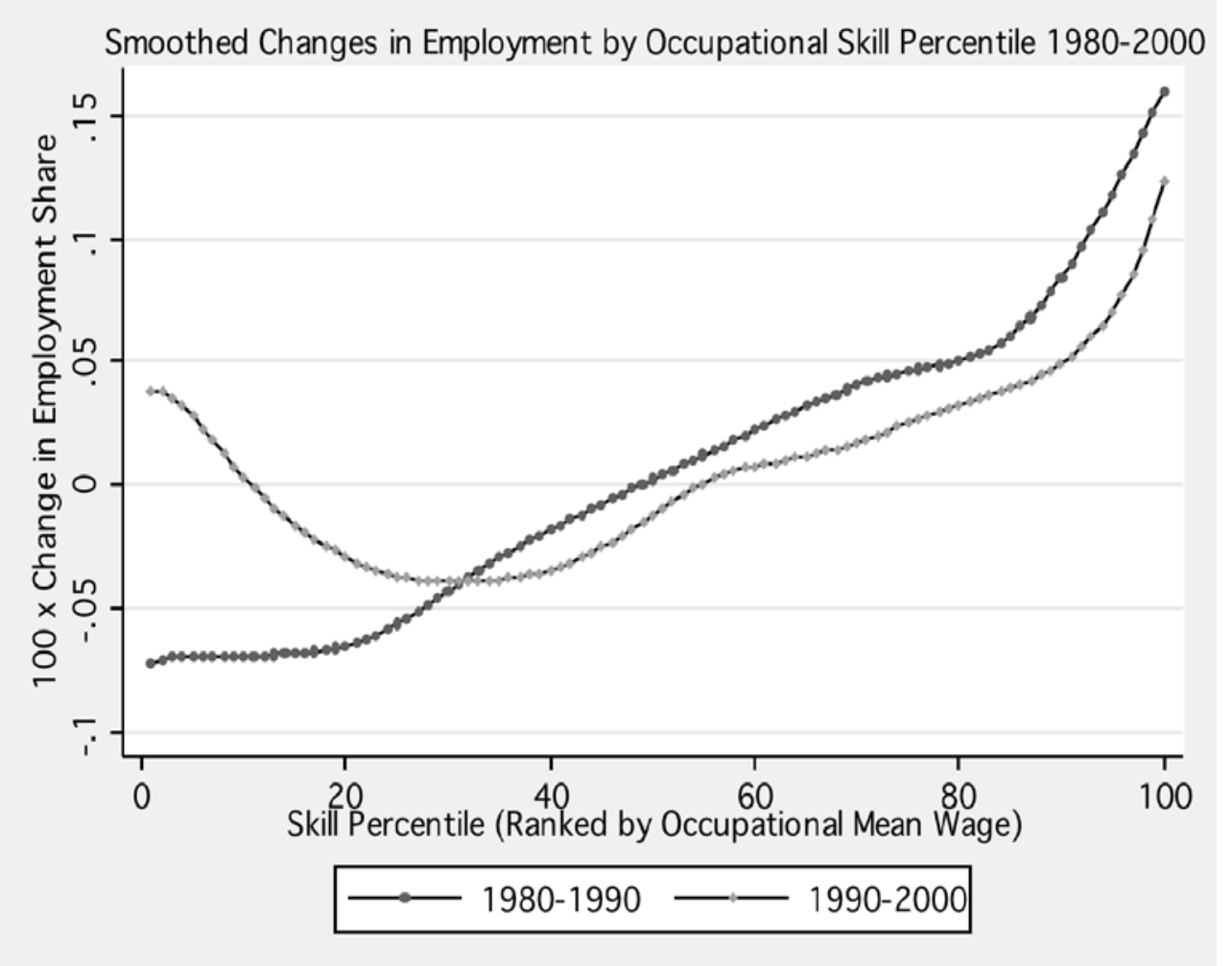

Figure 1.

Changes in Real Log Hourly Wages by Wage Percentile (panel A) and Changes in Employment Shares by Occupational Skill Percentile (panel B) 1980-1990 and 1990-2000 
Figure 2a

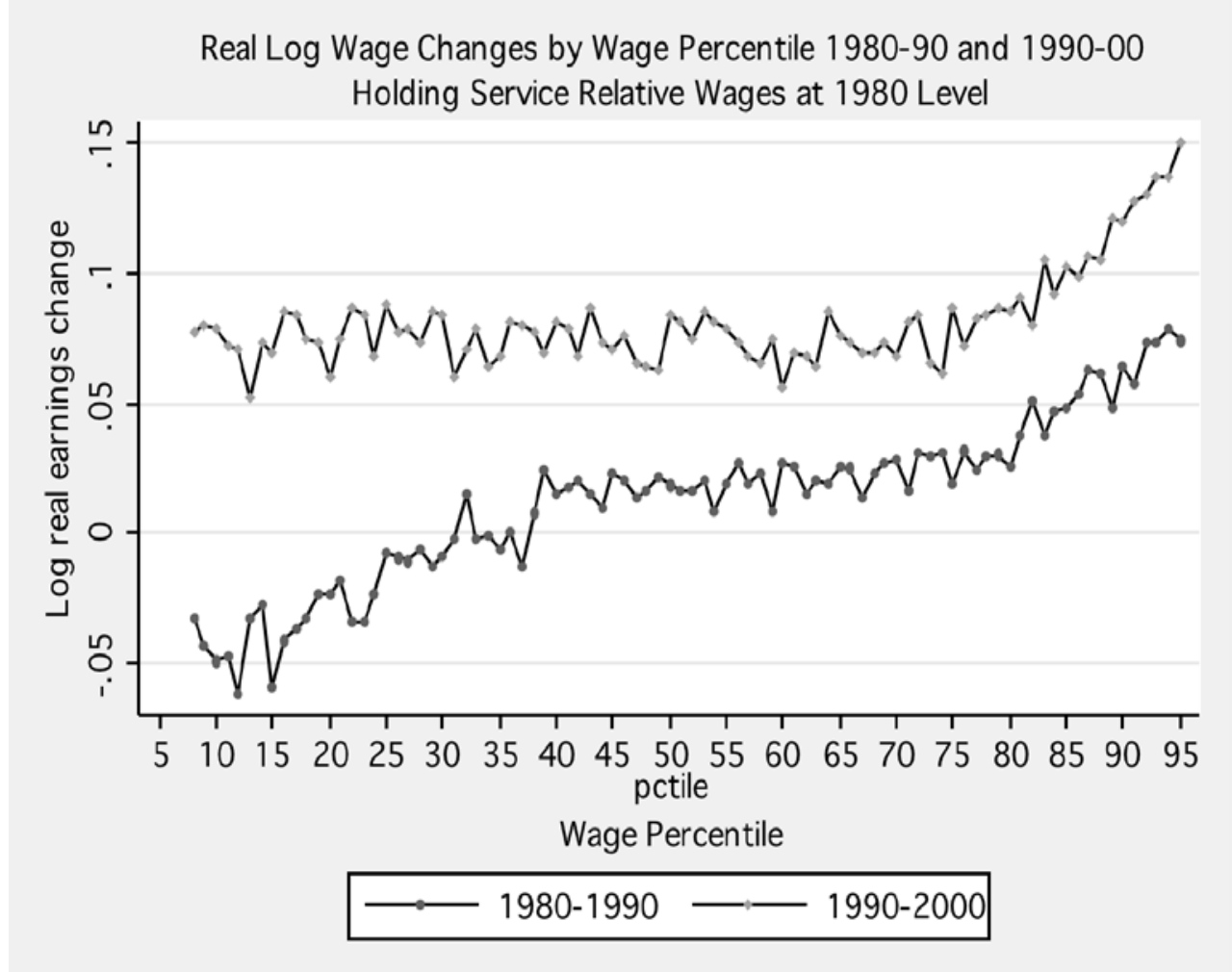

Figure $2 b$

Smoothed Changes in Employment by Occupational Skill Percentile 1980-2000 Service Employment Share at 1980 Level

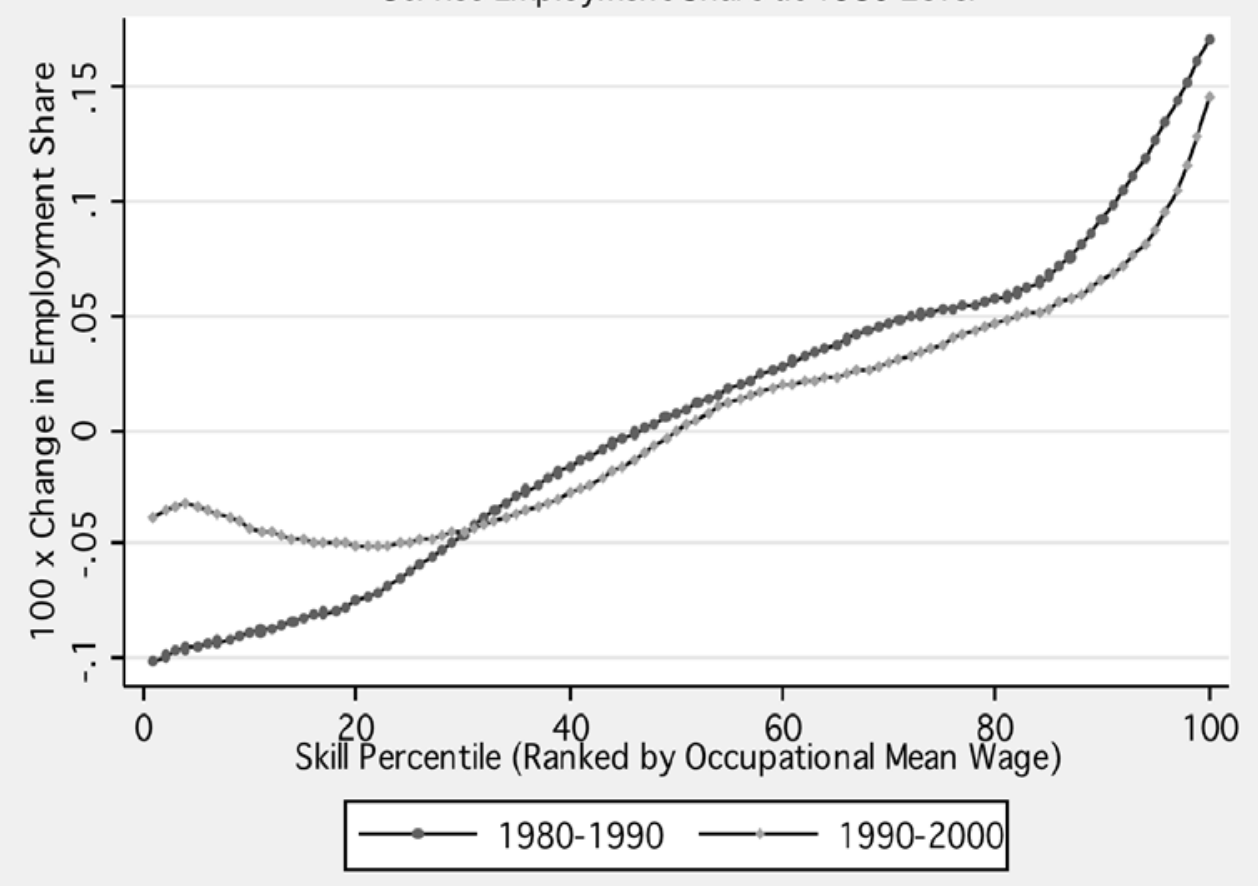

Figure 2.

Counterfactual Changes in Real Log Hourly Wages by Wage Percentile (panel A) and Changes in Employment Shares by Occupational Skill Percentile (panel B) 1980-1990 and 1990-2000, Holding Service Occupation Employment and Wages 
Figure 3a

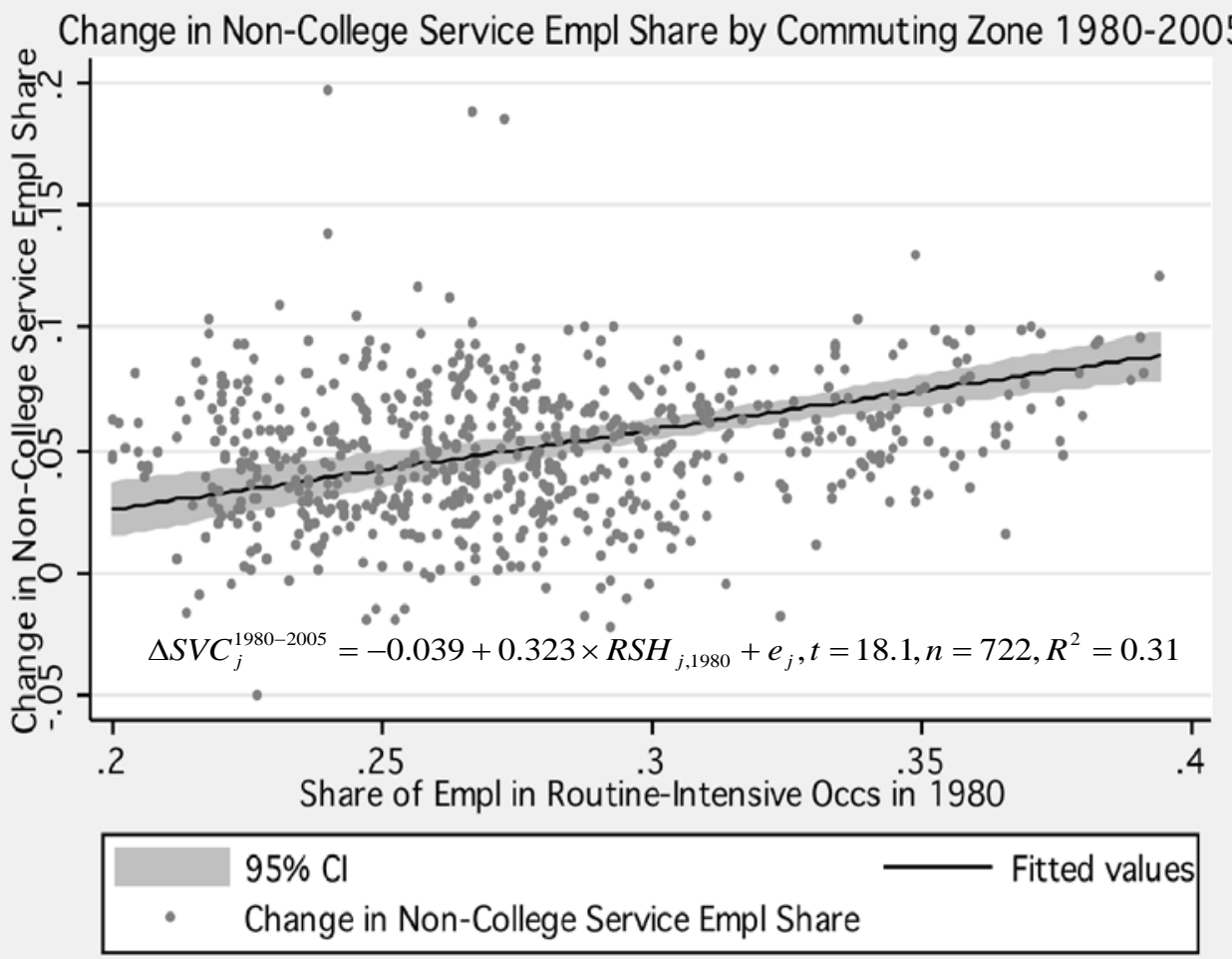

Figure 3b

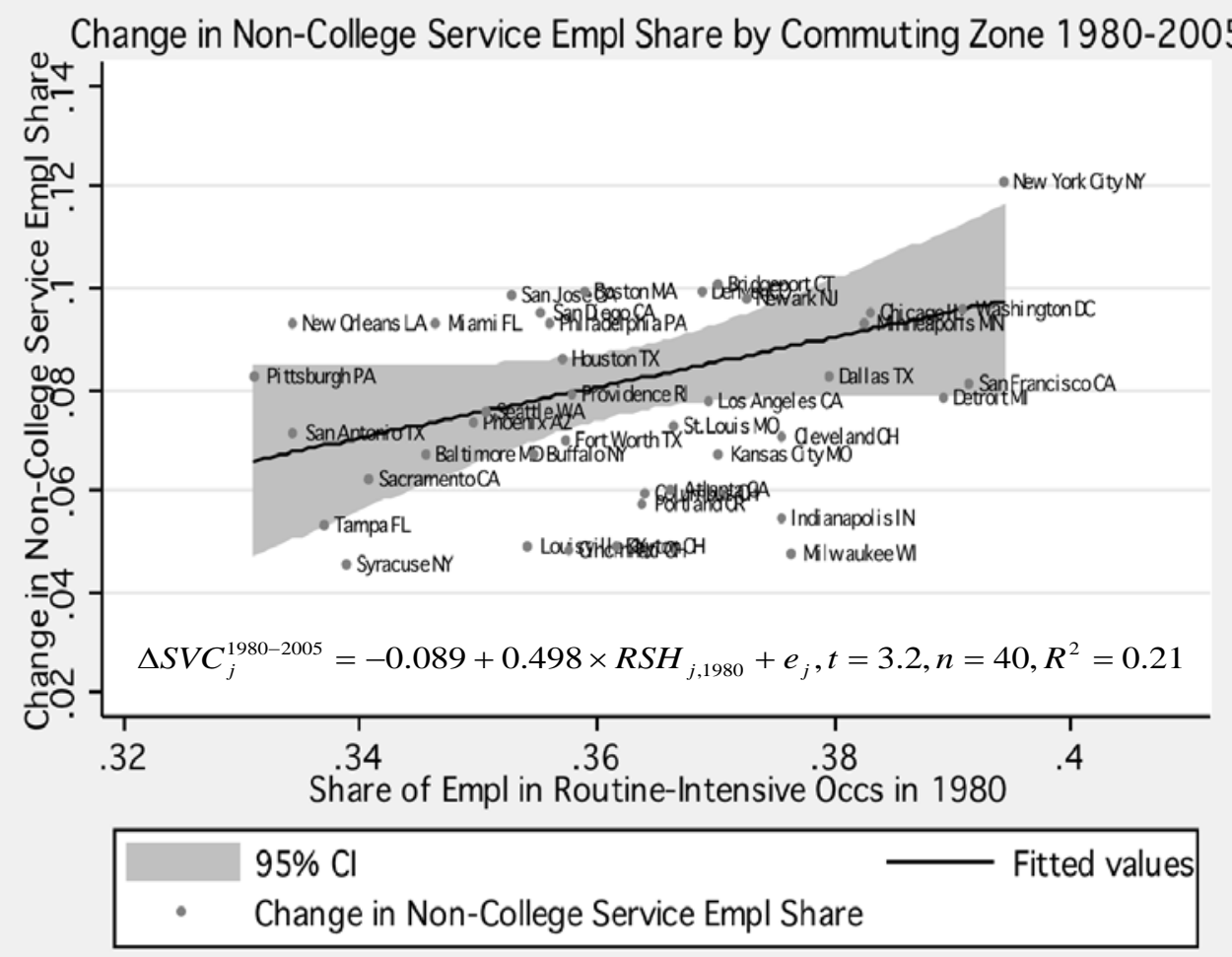

Figure 3.

Change in Non-College Employment Share in Service Occupation 1980 - 2005 Plotted Against Routine Employment Share in 1980 for Full Sample of Commuting Zones (Panel A) and the Set of Commuting Zones Containing at Least 1 Million 
Table 1. Levels and Changes in Employment Share and Mean Real Log Hourly Wages by Occupation, 1950-2005

\begin{tabular}{|c|c|c|c|c|c|c|c|c|}
\hline & \multicolumn{6}{|c|}{ Level } & \multicolumn{2}{|c|}{ Decadal Growth Rate } \\
\hline & 1950 & 1970 & 1980 & 1990 & 2000 & 2005 & $1950-80$ & 1980-05 \\
\hline & \multicolumn{8}{|c|}{ A. Share of Employment (\%) } \\
\hline Managers/Professionals & 20.1 & 21.4 & 23.8 & 27.8 & 29.5 & 30.4 & 5.8 & 10.3 \\
\hline Technicians/Sales/Admin & 21.7 & 26.6 & 28.9 & 30.8 & 30.1 & 29.5 & 10.1 & 0.8 \\
\hline Production/Craft/Repair & 13.3 & 13.9 & 14.3 & 12.4 & 12.6 & 11.9 & 2.4 & -6.9 \\
\hline Operators/Fabricat/Laborers & 22.8 & 22.6 & 19.2 & 15.5 & 13.4 & 12.6 & -5.5 & -15.6 \\
\hline Farming/Fishery/Forestry & 10.7 & 3.8 & 2.8 & 1.8 & 1.3 & 1.3 & -36.3 & -25.9 \\
\hline \multirow[t]{2}{*}{ Service Occupations } & 11.4 & 11.7 & 11.0 & 11.8 & 13.0 & 14.3 & -1.2 & 11.0 \\
\hline & \multicolumn{8}{|c|}{ B. Mean Real Log Hourly Wage (2004\$) } \\
\hline Managers/Professionals & 2.24 & 2.88 & 2.87 & 2.95 & 3.07 & 3.19 & 0.21 & 0.13 \\
\hline Technicians/Sales/Admin & 2.00 & 2.47 & 2.48 & 2.54 & 2.65 & 2.72 & 0.16 & 0.10 \\
\hline Production/Craft/Repair & 2.20 & 2.70 & 2.73 & 2.68 & 2.71 & 2.73 & 0.18 & 0.00 \\
\hline Operators/Fabricat/Laborers & 1.99 & 2.45 & 2.49 & 2.45 & 2.52 & 2.53 & 0.17 & 0.01 \\
\hline Farming/Fishery/Forestry & 0.93 & 1.80 & 1.88 & 2.09 & 2.21 & 2.24 & 0.32 & 0.14 \\
\hline Service Occupations & 1.51 & 2.06 & 2.16 & 2.21 & 2.32 & 2.33 & 0.22 & 0.07 \\
\hline \multicolumn{9}{|c|}{$\begin{array}{l}\text { Source: Census } 1 \% \text { samples for } 1950 \text { and } 1970 ; \text { Census } 5 \% \text { samples for } 1980,1990,2000 ; \text { American } \\
\text { Community Survey } 2005 \text {. Sample includes persons who were aged } 18-64 \text { and working in the prior year. } \\
\text { Occupation categories are defined according to Census classification. Hourly wages are defined as } \\
\text { yearly wage and salary income divided by the product of weeks worked times usual weekly hours. } \\
\text { Employment share is defined as share in total hours worked. Labor supply is measured as weeks } \\
\text { worked times usual weekly hours in prior year. All calculations use labor supply weights. }\end{array}$} \\
\hline
\end{tabular}


Table 2. Routine Employment Share and Growth of Service Employment within Commuting Zones, 1950 - 2005.

Dependent Variable: $10 \times$ Annual Change in Share of Non-College Employment in Service Occupations

\begin{tabular}{|c|c|c|c|c|c|c|c|c|}
\hline & $\begin{array}{c}1950- \\
1970 \\
\end{array}$ & & $\begin{array}{c}1970- \\
1980 \\
\end{array}$ & & $\begin{array}{c}1980- \\
1990 \\
\end{array}$ & & $\begin{array}{l}1990- \\
2000 \\
\end{array}$ & $\begin{array}{c}2000- \\
2005\end{array}$ \\
\hline $\begin{array}{l}\text { Share of Routine } \\
\text { Occs.-1 }\end{array}$ & $\begin{array}{l}-0.122 \\
(0.020)\end{array}$ & ** & $\begin{array}{c}0.032 \\
(0.034)\end{array}$ & & $\begin{array}{c}0.082 \\
(0.024)\end{array}$ & ** & $\begin{array}{c}0.084 \\
(0.037)\end{array}$ & $\begin{array}{c}* .321 \text { * } \\
(0.087)\end{array}$ \\
\hline Constant & $\begin{array}{c}0.022 \\
(0.003)\end{array}$ & ** & $\begin{array}{l}-0.032 \\
(0.009)\end{array}$ & ** & $\begin{array}{l}-0.014 \\
(0.007)\end{array}$ & * & $\begin{array}{l}-0.003 \\
(0.011)\end{array}$ & $\begin{array}{l}-0.042 \\
(0.027)\end{array}$ \\
\hline $\begin{array}{l}\text { State dummies } \\
\mathrm{R}^{2}\end{array}$ & $\begin{array}{l}\text { Yes } \\
0.495\end{array}$ & & $\begin{array}{l}\text { Yes } \\
0.435\end{array}$ & & $\begin{array}{l}\text { Yes } \\
0.528\end{array}$ & & $\begin{array}{c}\text { Yes } \\
0.596\end{array}$ & Yes \\
\hline
\end{tabular}

$\mathrm{N}=722$ commuting zones. Robust standard errors in parentheses are clustered on state. Models are weighted by start of period commuting zone share of national population. Routine occupations are defined the occupations with largest routine task / manual task ratios that account for one third of overall employment in 1980. $\sim p \leq 0.10,{ }^{*} p \leq 0.05,{ }^{* *} p \leq 0.01$. 
Table 3. Routine Employment Share and Growth of Service Employment within Commuting Zones, 1950 - 2005: Stacked First Differences.

Dependent Variable: $10 \times$ Annual Change in Share of Non-College Employment in Service Occupations

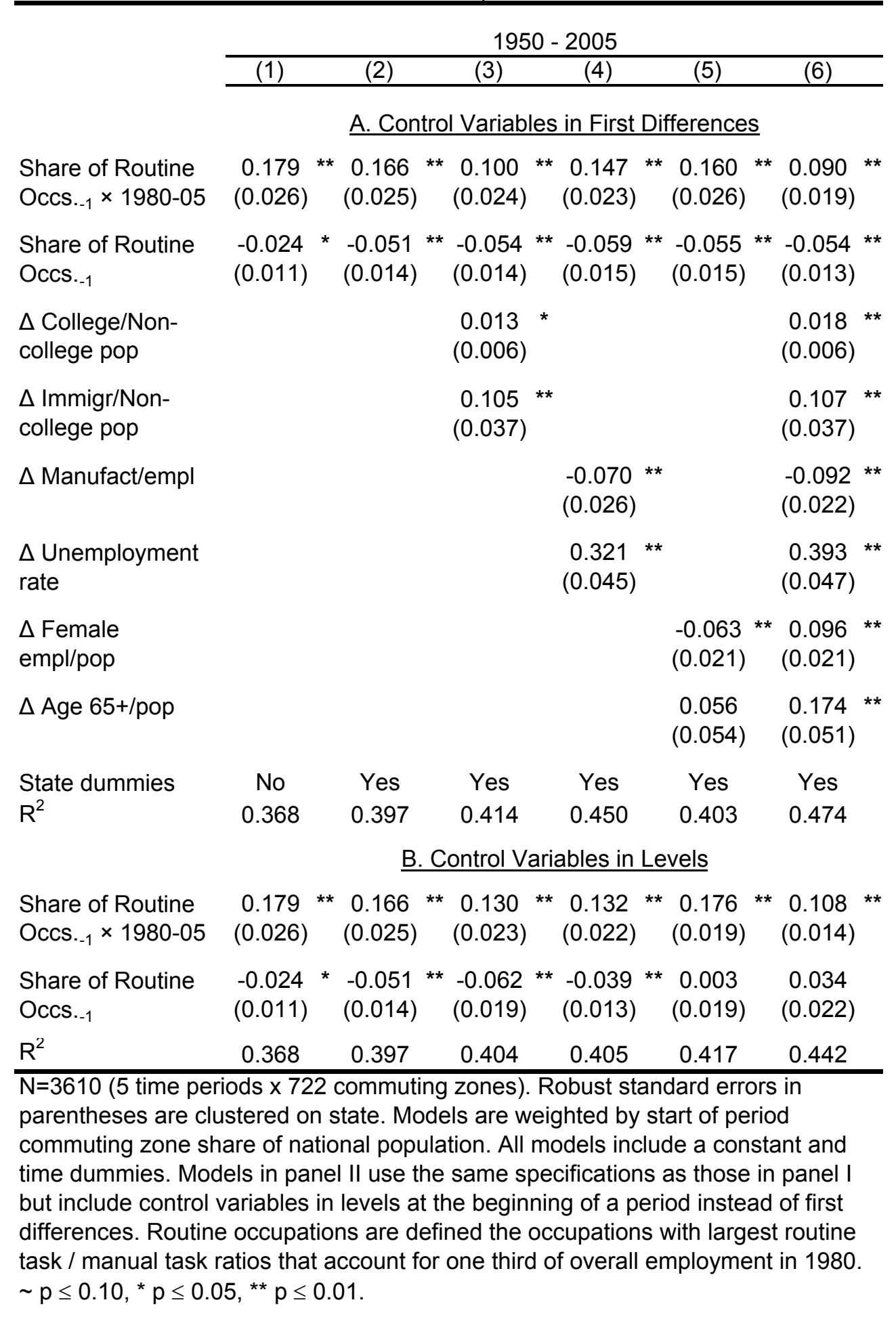


Table 4. Routine Employment Share and Growth of Service

Employment within Commuting Zones, 1950 - 2005.

Dependent Variable: $10 \times$ Annual Change in Share of Population

Group's Non-College Employment in Service Occupations

\begin{tabular}{|c|c|c|c|c|c|c|}
\hline & Males & Females & & $\begin{array}{c}\text { US } \\
\text { Borns }\end{array}$ & $\begin{array}{c}\text { Foreign } \\
\text { Borns }\end{array}$ & \\
\hline $\begin{array}{l}\text { Share of Routine } \\
\text { Occs. }-1 \times 1980-05\end{array}$ & $\begin{array}{c}0.129 \\
(0.028)\end{array}$ & ** $\begin{array}{c}0.084 \\
(0.070)\end{array}$ & & $\begin{array}{c}0.046 \\
(0.022)\end{array}$ & $\begin{array}{c}* \\
0.323 \\
(0.082)\end{array}$ & ** \\
\hline $\begin{array}{l}\text { Share of Routine } \\
\text { Occs.-1 }\end{array}$ & $\begin{array}{l}-0.017 \\
(0.014)\end{array}$ & $\begin{array}{c}0.097 \\
(0.034)\end{array}$ & ** & $\begin{array}{l}-0.043 \\
(0.017)\end{array}$ & $\begin{array}{l}* 0.100 \\
(0.059)\end{array}$ & $\sim$ \\
\hline Constant & $\begin{array}{c}0.005 \\
(0.003)\end{array}$ & $\begin{array}{r}-0.049 \\
(0.009)\end{array}$ & ** & $\begin{array}{c}0.015 \\
(0.003)\end{array}$ & $\begin{array}{cc}* * & 0.024 \\
& (0.013)\end{array}$ & $\sim$ \\
\hline $\begin{array}{l}\text { State dummies } \\
\mathrm{R}^{2}\end{array}$ & $\begin{array}{c}\text { Yes } \\
0.238\end{array}$ & $\begin{array}{c}\text { Yes } \\
0.514\end{array}$ & & $\begin{array}{c}\text { Yes } \\
0.284\end{array}$ & $\begin{array}{c}\text { Yes } \\
0.052\end{array}$ & \\
\hline \multicolumn{7}{|c|}{$\begin{array}{l}\mathrm{N}=3610 \text { ( } 5 \text { time periods } \times 722 \text { commuting zones). Robust standard } \\
\text { errors in parentheses are clustered on state. Models are weighted by } \\
\text { start of period commuting zone share of national population. Routine } \\
\text { occupations are defined the occupations with largest routine task / } \\
\text { manual task ratios that account for one third of overall employment in } \\
\text { 1980. } \sim \mathrm{p} \leq 0.10,{ }^{*} \mathrm{p} \leq 0.05,{ }^{* *} \mathrm{p} \leq 0.01 \text {. }\end{array}$} \\
\hline
\end{tabular}


Table 5. Growth of Service Employment by Tercile of Predicted Routine Share, 1980 - 2005.

Dependent Variable: $10 \times$ Annual Change in Share of Non-College Employment in Service Occupations

\begin{tabular}{|c|c|c|c|c|}
\hline & \multicolumn{4}{|c|}{ C'zones by Predicted 1980 Routine Share } \\
\hline & All & Top 1/3 & $\begin{array}{c}\text { Middle } \\
1 / 3 \\
\end{array}$ & $\begin{array}{c}\text { Bottom } \\
1 / 3 \\
\end{array}$ \\
\hline $\begin{array}{l}\text { Residual Share of } \\
\text { Routine Occs.-1 }\end{array}$ & $\begin{array}{c}0.122 \\
(0.054)\end{array}$ & $\begin{array}{c}0.100 \\
(0.068)\end{array}$ & $\begin{array}{c}0.119 \\
(0.051)\end{array}$ & $\begin{array}{c}* \\
* \\
(0.083)\end{array}$ \\
\hline $\begin{array}{l}\mathrm{N} \\
\mathrm{R}^{2}\end{array}$ & $\begin{array}{l}2166 \\
0.061\end{array}$ & $\begin{array}{c}723 \\
0.089\end{array}$ & $\begin{array}{c}720 \\
0.028\end{array}$ & $\begin{array}{c}723 \\
0.021\end{array}$ \\
\hline $\begin{array}{l}\text { Predicted routine sh } \\
\text { regression of routin } \\
\text { of immigrants amor } \\
\text { unemployment rate } \\
\text { above age } 65 \text {, and } \\
\text { residuals of that res } \\
\text { are clustered on sta } \\
\text { commuting zone sh } \\
\text { and time dummies. }\end{array}$ & $\begin{array}{l}\text { is based } \\
\text { are on c } \\
\text { n-colleg } \\
\text { ale labo } \\
\text { dummi } \\
\text { ion. Rob } \\
\text { lodels a } \\
\text { ff nation } \\
0.10 \text {, * }\end{array}$ & $\begin{array}{l}\text { on the pred } \\
\text { ollege/non-c } \\
\text { e population } \\
r \text { force partic } \\
\text { es. Residual } \\
\text { ust standarc } \\
\text { re weighted } \\
\text { al populatior } \\
p \leq 0.05 \text {, ** }\end{array}$ & $\begin{array}{l}\text { d values } \\
\text { ge popul } \\
\text { anufactu } \\
\text { tion, pop } \\
\text { tine sha } \\
\text { rors in p } \\
\text { start of } p \\
\text { d contai } \\
0.01\end{array}$ & $\begin{array}{l}\text { from a } \\
\text { lation, share } \\
\text { ring share, } \\
\text { ulation share } \\
\text { re equals the } \\
\text { arentheses } \\
\text { eriod } \\
\text { n a constant }\end{array}$ \\
\hline
\end{tabular}


Table 6. Predicting Changes in Service Occupation Employment using Proxies for Income and Substitution Effects. Dependent Variables: $10 \times$ Annual Change in Share of Non-College Employment in Service Occupations, 1980-2005

\begin{tabular}{|c|c|c|c|c|c|c|}
\hline & (1) & $(2)$ & (3) & (4) & (5) & (6) \\
\hline$\Delta \ln ($ P90) Weekly & $\begin{array}{c}0.013 \\
(0.015)\end{array}$ & $\begin{array}{l}-0.012 \\
(0.015)\end{array}$ & & & & \\
\hline $\begin{array}{l}\triangle \text { Avg Annual Hours } \\
\text { per Coll Grad / } 2080\end{array}$ & & & $\begin{array}{l}-0.111 \\
(0.032)\end{array}$ & $\begin{array}{l}-0.120 \\
(0.032)\end{array}$ & & \\
\hline $\begin{array}{l}\triangle \text { Avg Annual Hours } \\
\text { per Male Coll Grad / }\end{array}$ & & & & & $\begin{array}{l}-0.064 * \\
(0.018)\end{array}$ & \\
\hline $\begin{array}{l}\Delta \text { Avg Annual Hours } \\
\text { per Female Coll Grad / }\end{array}$ & & & & & & $\begin{array}{l}-0.081 * \\
(0.024)\end{array}$ \\
\hline $\begin{array}{l}\text { Share of Routine Occs. } \\
1\end{array}$ & & $\begin{array}{l}0.140 \\
(0.024)\end{array}$ & & $\begin{array}{c}0.138 \\
(0.025)\end{array}$ & ** $0.145 *$ & ** 0.121 ** \\
\hline $\mathrm{R}^{2}$ & 0.166 & 0.194 & 0.185 & 0.216 & 0.205 & 0.211 \\
\hline
\end{tabular}


Table 7. Changes in Employment Shares in Routine and NonRoutine Occupations within Commuting Zones, 1980 - 2005.

Dependent Variable: $10 \times$ Annual Change in Education

Group's Share of Employment in Routine or Non-Routine

\begin{tabular}{ccc}
\hline All & & Non- \\
Workers & College & College \\
\hline$(1)$ & $(2)$ & $(3)$ \\
\hline
\end{tabular}

A. $\Delta$ Share Routine Occupations

\begin{tabular}{|c|c|c|c|c|c|c|}
\hline $\begin{array}{l}\text { Share of Routine } \\
\text { Occs.-1 }\end{array}$ & $\begin{array}{l}-0.238 \\
(0.013)\end{array}$ & & $\begin{array}{l}-0.162 \\
(0.014)\end{array}$ & & $\begin{array}{l}-0.277 \\
(0.018)\end{array}$ & ** \\
\hline & \multicolumn{6}{|c|}{ B. $\Delta$ Share High-Skill Non-Routine } \\
\hline \multirow[t]{2}{*}{$\begin{array}{l}\text { Share of Routine } \\
\text { Occs.-1 }\end{array}$} & $\begin{array}{c}0.047 \\
(0.018)\end{array}$ & ** & $\begin{array}{c}0.078 \\
(0.019)\end{array}$ & ** & $\begin{array}{l}-0.034 \\
(0.023)\end{array}$ & \\
\hline & \multicolumn{6}{|c|}{ C. $\Delta$ Share Low-Skill Non-Routine Occs } \\
\hline $\begin{array}{l}\text { Share of Routine } \\
\text { Occs. }-1\end{array}$ & $\begin{array}{c}0.190 \\
(0.022)\end{array}$ & ** & $\begin{array}{c}0.083 \\
(0.014)\end{array}$ & ** & $\begin{array}{c}0.311 \\
(0.030)\end{array}$ & ** \\
\hline \multicolumn{7}{|c|}{$\begin{array}{l}\mathrm{N}=2166 \text { ( } 3 \text { time periods } \times 722 \text { commuting zones). Robust } \\
\text { standard errors in parentheses are clustered on state. Models } \\
\text { are weighted by start of period commuting zone share of } \\
\text { national population. All models include a constant, time and } \\
\text { state dummies. Routine occupations are defined the } \\
\text { occupations with largest routine task / manual task ratios that } \\
\text { account for one third of overall employment in 1980. } \sim p \leq \\
0.10,{ }^{*} p \leq 0.05,{ }^{* *} p \leq 0.01 \text {. }\end{array}$} \\
\hline
\end{tabular}


Table 8: Routine Task Intensity and Computer Adoption 1980-2000.

Dependent Variable: 'Adjusted PCs per Employee' (Doms and Lewis 2006)

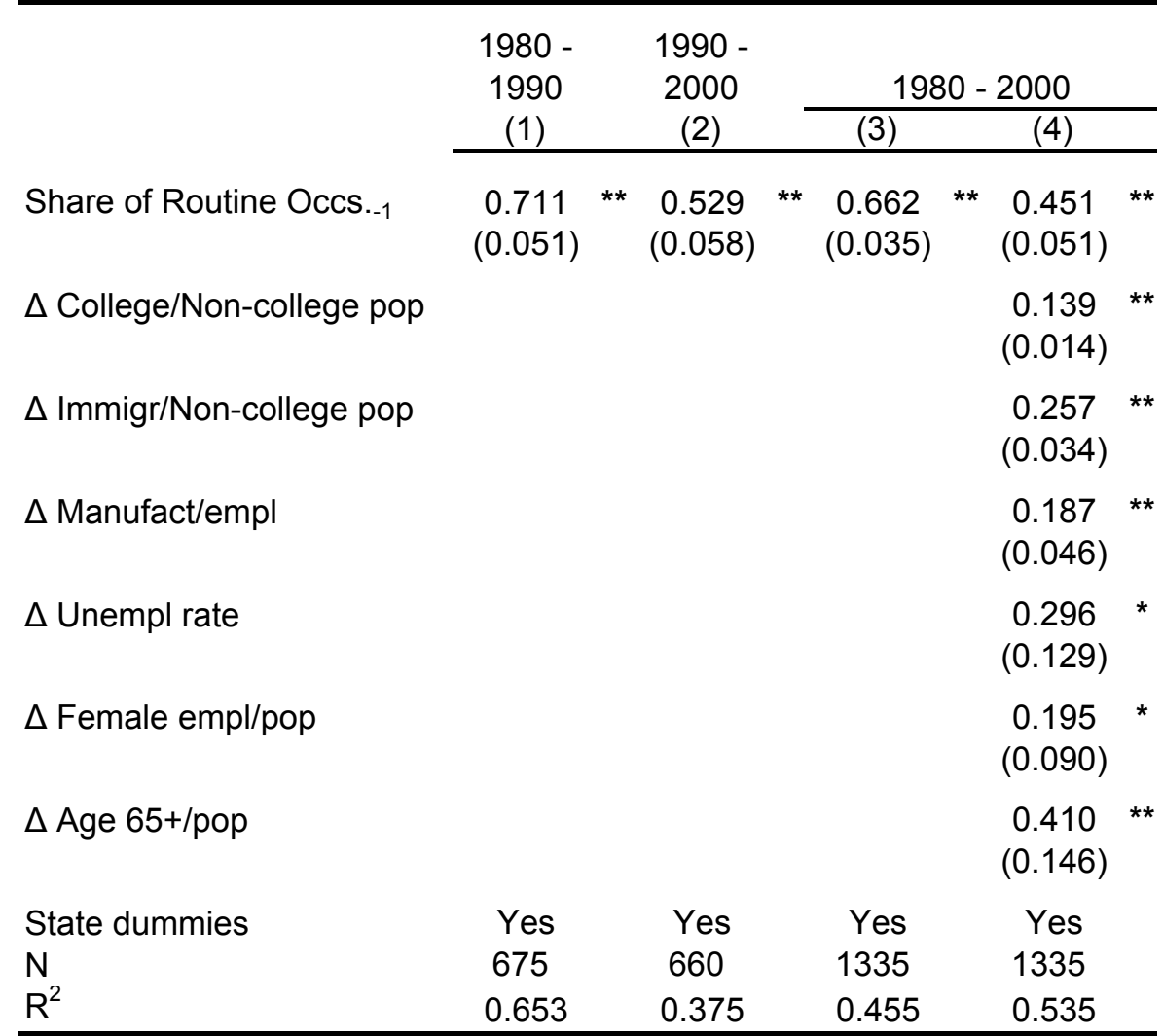

The Doms-Lewis measure of computer adoption reflects the number of personal computers per employee, controlling for 950 industry/establishment interactions. Data for computer adoption in commuting zones is available to us for the years 1990 and 2002; we assume zero computers per worker in 1980 and use 5/6 of the change in computer adoption between 1990 and 2002 as our measure for computer adoption during the 1990s. Models are weighted by start of period commuting zone share of national population. All models include a constant and time dummies. $\sim p \leq 0.10,{ }^{*} p \leq 0.05,{ }^{* *} p \leq 0.01$. 
Table 9. Routine Task Intensity and Change in Wage Inequality, 1980 - 2005. Dependent Variable: $10 \times$ Annual Change in Wage Inequality

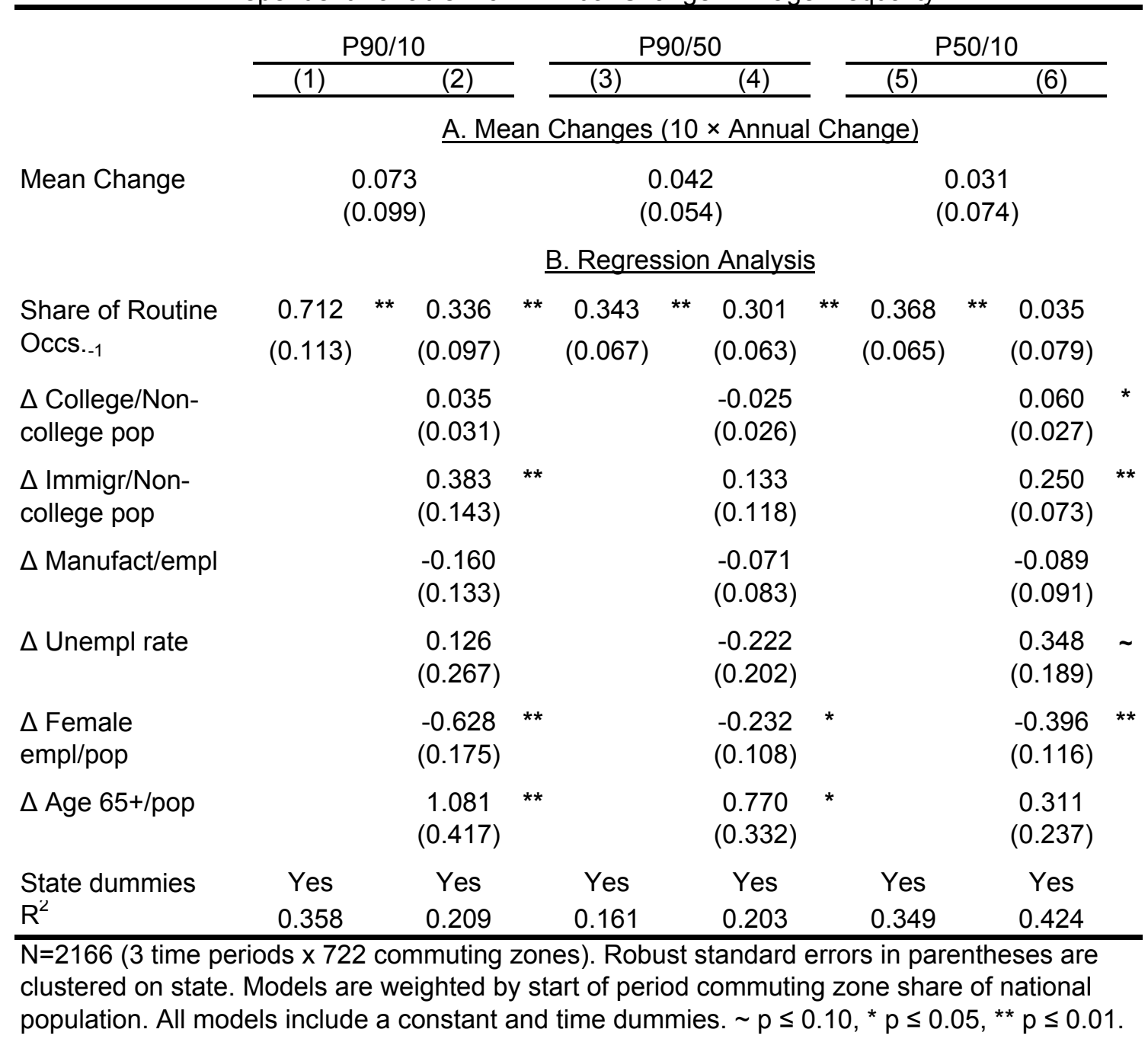


Table 10. Routine Employment Share and Wage Changes by Major Occupation Groups, 1980 - 2005.

Dependent Variable: Log Real Hourly Wage.

Microdata Estimates using Pooled 1980/2005 Census and ACS Samples

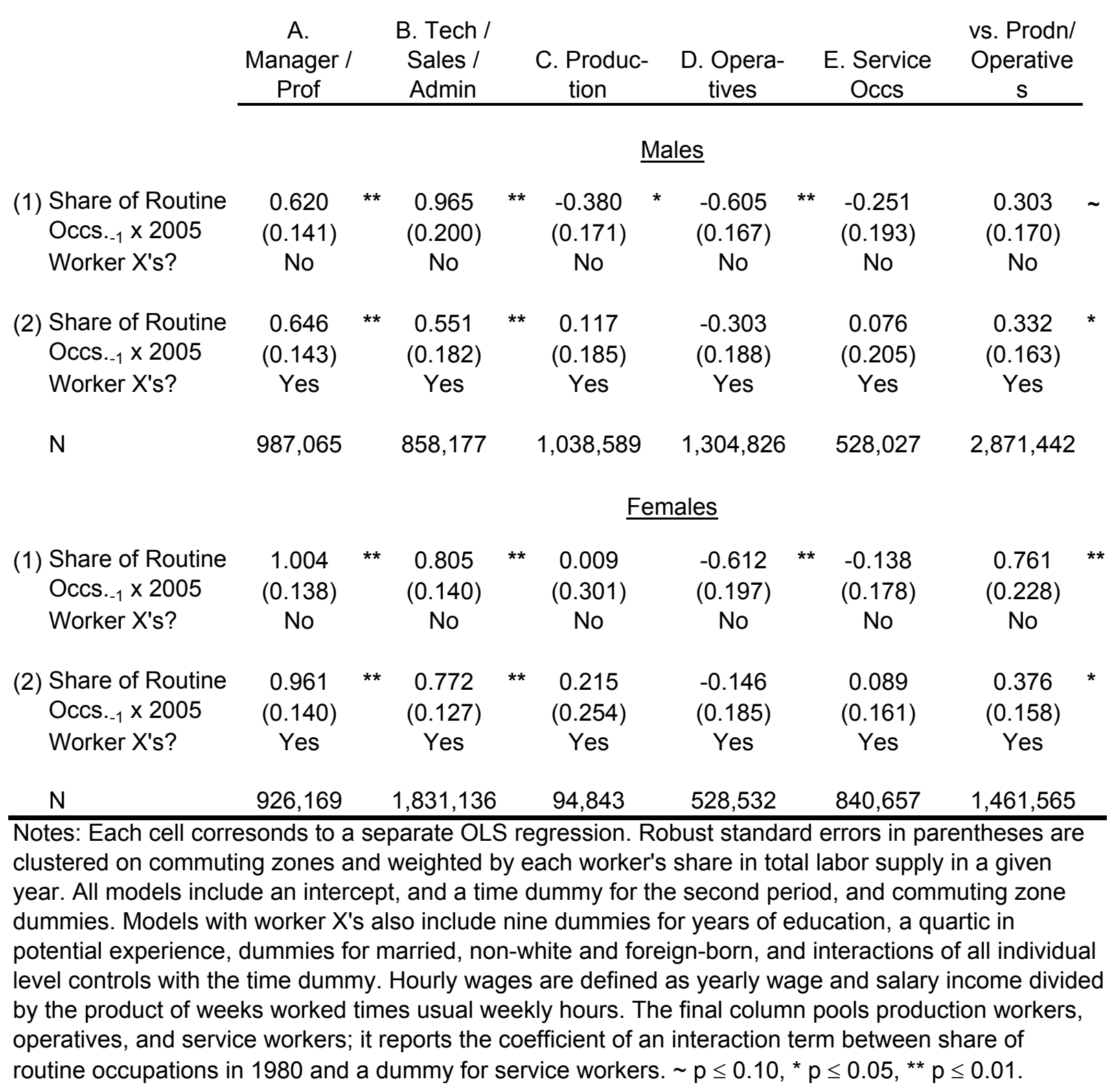




\section{A. Characteristics of Routine and Non-Routine Occupations in 1980}

\begin{tabular}{lccc} 
& Routine Occupations & High Wage Non- & Routine \\
\cline { 2 - 4 } Average Ln Hourly Wa! & 2.53 & 2.84 & 2.29 \\
Share College Educate & 0.45 & 0.54 & 0.27 \\
Average Routine Task & 1.18 & -0.56 & -0.63
\end{tabular}

\section{B. Occupations Ranked by Routine-Task-Intensity and Employment}

\section{Occupations with Highest RTI Scores}

1 Secretaries and Stenographers

2 Bank Tellers

3 Pharmacists

4 Payroll and Timekeeping Clerks

5 Motion Picture Projectionists *

6 Boilermakers

7 Butchers and Meat Cutters

8 Accountants and Auditors

9 Actuaries

10 Proofreaders

\section{Occupations with Lowest RTI Scores}

1 Parking Lot Attendants

2 Fire Fighting, Prevention and Inspection *

3 Bus Drivers

4 Taxi Cab Drivers and Chauffeurs

5 Public Transp. Attendants, Inspectors *

6 Police and Detectives, Public Service *

7 Truck, Delivery, and Tractor Drivers

8 Garbage and Recyclable Material Collector

9 Crossing Guards *

10 Railroad Coupler, Brake, Switch Operators 10 Textile Sewing Machine Operators

\section{Largest High-Wage Non-Routine Occs}

1 Truck, Delivery, and Tractor Drivers

2 Production Supervisors or Foremen

3 Primary School Teachers

4 Registered Nurses

5 Supervisors of Construction Work

6 Secondary School Teachers

7 Electricians

8 Engineering Technicians

9 Physicians

10 Police and Detectives, Public Service *

\section{Largest Low-Wage Non-Routine Occs}

1 Retail Salespersons and Sales Clerks

2 Sales Supervisors and Proprietors

3 Janitors *

4 Farmers

5 Health and Nursing Aides *

6 Carpenters

7 Automobile Mechanics and Repairers

8 Production Checkers, Graders, and Sorters

9 Waiters and Waitresses *

Notes: Asterisk denotes service occupations according to the Census occupational classification. Real hourly wages are inflated to 2004. The Routine Task Index (RTI) measures the log routine/manual task ratio for each detailled occupation. The distribution of $\mathrm{RTI}$ in the labor market in 1980 is standardized to a mean of zero and a standard deviation of one. For occupations with equal RTI score, ranking ties are split by giving a higher ranking to the occupation with larger share in total US employment in 1980. High and low-wage nonroutine occupations are grouped by 1980 mean occupational wages. Each group contain onethird of 1980 employment, with the remaining third of 1980 employment classified as routine task-intensive. Residual occupations groups (miscellaneous, other, and not elsewhere classified) are excluded from the ranking. 
Appendix Table 2. Routine Employment Share and Growth of Employment in Detailled Service Occupations within Commuting Zones, 1950 - 2005: Stacked First Differences.

Dependent Variable: $10 \times$ Annual Change in Share of Non-College Employment in Specific Service Occupation

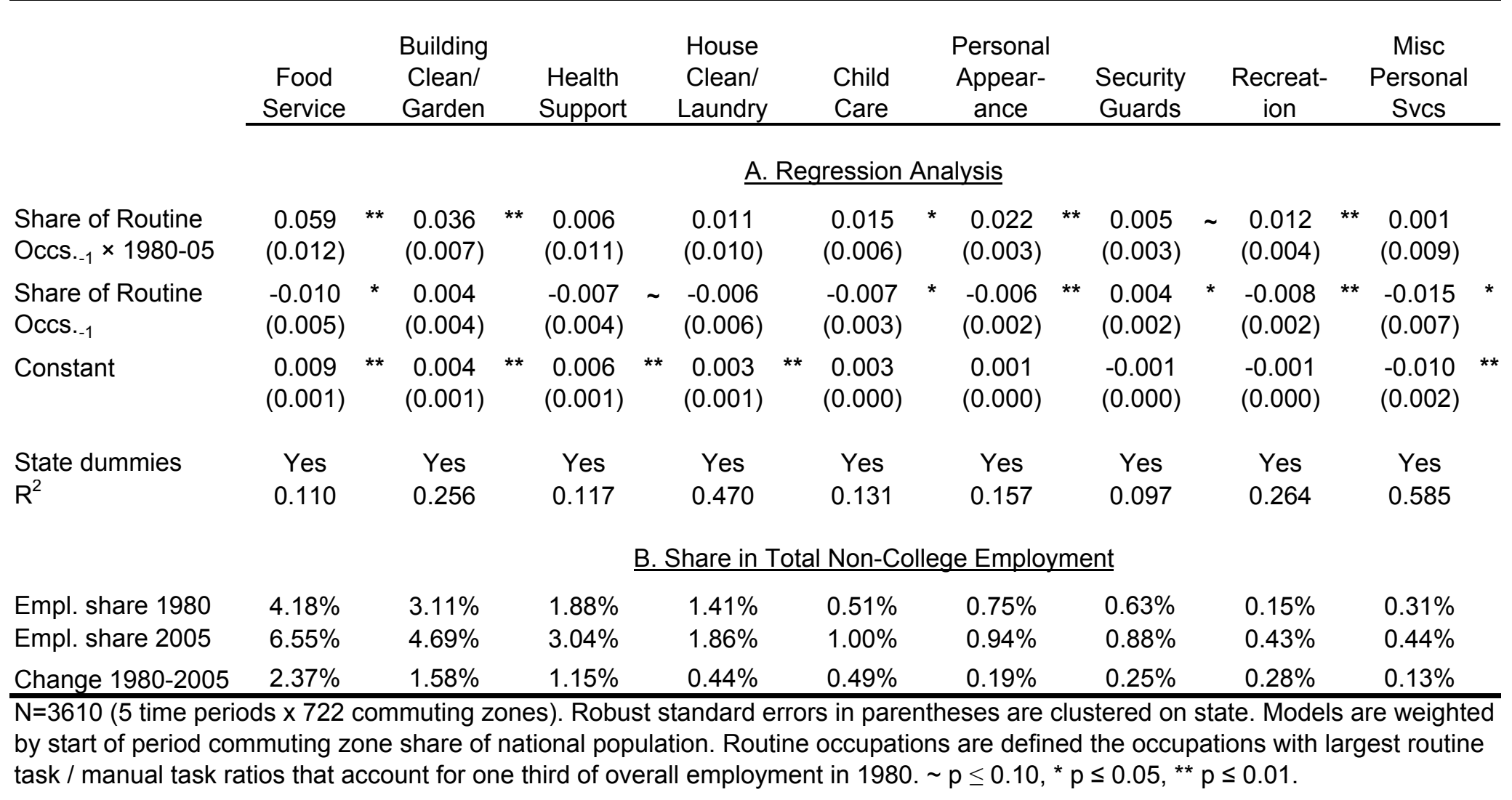




\begin{tabular}{|c|c|c|c|c|c|c|c|c|c|c|c|}
\hline & $(1)$ & & $(2)$ & (3) & (4) & (5) & (6) & $(7)$ & \multicolumn{3}{|c|}{ (8) } \\
\hline $\begin{array}{l}\text { College/Non- } \\
\text { college pop } 1980\end{array}$ & & & $\begin{array}{c}0.176 \\
(0.020)\end{array}$ & ** & & & & & & $\begin{array}{c}0.067 \\
(0.020)\end{array}$ & $* *$ \\
\hline $\begin{array}{l}\text { Immigr/Non- } \\
\text { college pop } 1980\end{array}$ & & & & $\begin{array}{c}0.308 \\
(0.087)\end{array}$ & & & & & & $\begin{array}{c}0.216 \\
(0.068)\end{array}$ & $* *$ \\
\hline $\begin{array}{l}\text { Manufact/empl } \\
1980\end{array}$ & & & & & $\begin{array}{l}-0.005 \\
(0.069)\end{array}$ & & & & & $\begin{array}{l}-0.002 \\
(0.042)\end{array}$ & \\
\hline $\begin{array}{l}\text { Unemployment } \\
\text { rate } 1980\end{array}$ & & & & & & -1.468 & $* *$ & & & $\begin{array}{c}0.225 \\
(0.169)\end{array}$ & \\
\hline $\begin{array}{l}\text { Female empl/pop } \\
1980\end{array}$ & & & & & & & $\begin{array}{c}0.648 \\
(0.044)\end{array}$ & & & $\begin{array}{c}0.471 \\
(0.074)\end{array}$ & $* *$ \\
\hline $\begin{array}{l}\text { Age } 65+/ \text { pop } \\
1980\end{array}$ & & & & & & & & $\begin{array}{l}-0.909 \\
(0.313)\end{array}$ & ** & $\begin{array}{l}-0.295 \\
(0.099)\end{array}$ & ** \\
\hline Constant & $\begin{array}{l}0.291 \\
0.000\end{array}$ & ** & $\begin{array}{c}0.213 \\
(0.009)\end{array}$ & $\begin{array}{c}* * \quad \\
0.288 \\
(0.001)\end{array}$ & $\begin{array}{cc}* * & 0.292 \\
& (0.019)\end{array}$ & $\begin{array}{c}* * \\
0.398 \\
(0.013)\end{array}$ & ** $\begin{array}{r}-0.030 \\
(0.022)\end{array}$ & $\begin{array}{c}0.394 \\
(0.035)\end{array}$ & ** & $\begin{array}{c}0.043 \\
(0.035)\end{array}$ & \\
\hline $\begin{array}{l}\mathrm{R}^{2} \\
\text { State dummies }\end{array}$ & $\begin{array}{l}0.395 \\
\text { Yes }\end{array}$ & & $\begin{array}{l}0.660 \\
\text { Yes }\end{array}$ & $\begin{array}{l}0.484 \\
\text { Yes }\end{array}$ & $\begin{array}{l}0.395 \\
\text { Yes }\end{array}$ & $\begin{array}{l}0.560 \\
\text { Yes }\end{array}$ & $\begin{array}{l}0.721 \\
\text { Yes }\end{array}$ & $\begin{array}{l}0.531 \\
\text { Yes }\end{array}$ & & $\begin{array}{l}0.816 \\
\text { Yes }\end{array}$ & \\
\hline
\end{tabular}

$\mathrm{n}=722$ Commuting Zones. Robust standard errors in parentheses are clustered on state. Models are weighted by start of period commuting zone share of national population and include an intercept. $\sim \mathrm{p} \leq$ $0.10,{ }^{*} \mathrm{p} \leq 0.05,{ }^{* *} \mathrm{p} \leq 0.01$. 